OPEN ACCESS

Edited by:

Jean El Cheikh,

American University of Beirut Medical

Center, Lebanon

Reviewed by:

Riad El Fakih,

King Faisal Specialist Hospital \&

Research Centre,

Saudi Arabia

Francianne Gomes Andrade,

Consultant Panama City, Panama

Pier Paolo Piccaluga,

University of Bologna, Italy

${ }^{*}$ Correspondence:

Chun-fung Sin

scf185@pathology.hku.hk

Specialty section:

This article was submitted to

Hematologic Malignancies,

a section of the journal

Frontiers in Oncology

Received: 31 July 2021 Accepted: 04 November 2021 Published: 29 November 2021

Citation:

Sin C-f and Man P-hM (2021) Early TCell Precursor Acute Lymphoblastic

Leukemia: Diagnosis, Updates in Molecular Pathogenesis, Management, and Novel Therapies.

Front. Oncol. 11:750789.

doi: 10.3389/fonc.2021.750789

\section{Early T-Cell Precursor Acute Lymphoblastic Leukemia: Diagnosis, Updates in Molecular Pathogenesis, Management, and Novel Therapies}

\author{
Chun-fung Sin * and Pui-hei Marcus Man \\ Department of Pathology, University of Hong Kong, Hong Kong, Hong Kong SAR, China
}

Early T-cell precursor acute lymphoblastic leukemia (ETP-ALL) is a distinct subtype of T lymphoblastic leukemia (T-ALL) identified in 2009, due to its unique immunophenotypic and genomic profile. The outcome of patients was poor in earlier studies, and they were prone to have induction failure, with more frequent relapse/refractory disease. Recent advances had been made in discoveries of genetic aberrations and molecular pathogenesis of ETP-ALL. However, the diagnosis and management of ETP-ALL is still challenging. There are limited choices of novel therapies so far. In this review article, it highlighted the diagnostic issue of ETP-ALL, pitfall in diagnosis, and strategy of accurate diagnosis. The review also summarized current understanding of molecular mechanism of leukemogenesis. The emerging role of risk-adapted therapy and allogenic stem cell transplant in optimizing the outcome of patients with ETP-ALL was discussed. Finally, some potential novel therapies were proposed based on the current understanding of molecular pathogenesis.

Keywords: ETP-ALL, T lymphoblastic leukemia, early T-cell precursor acute lymphoblastic leukemia, diagnosis, molecular pathogenesis, novel therapies

\section{INTRODUCTION}

$\mathrm{T}$ lymphoblastic leukemia (T-ALL) is an aggressive hematological malignancy, which accounts for $15 \%$ of pediatric ALL and $25 \%$ of adult ALL cases (1). Outcomes are favorable in the pediatric population with $75 \%-80 \%$ achieving long-term survival (2). However, the prognosis is particularly poor in the adult population with only $50 \%-60 \%$ achieving long-term survival (3). Moreover, a substantial proportion of patients relapse after chemotherapy and the outcome following relapse/ refractory disease is dismal.

Early T-cell precursor acute lymphoblastic leukemia (ETP-ALL) is a distinct entity as defined by World Health Organization (WHO) classification 2017 version due to its unique immunophenotypic and genomic profile compared with other subtypes of T-ALL (4). This entity comprises $5 \%-17 \%$ and $7.4 \%$ of pediatric and adult ALL, respectively (5). Recent discovery of 
genetic aberrations in ETP-ALL will help to better understand its molecular pathogenesis. However, the diagnosis and management of ETP-ALL is still challenging, especially for relapse/refractory disease. ETP-ALL has been reported to have adverse outcome in earlier studies for pediatric and adult patients compared with other subtypes of T-ALL. This review will summarize the diagnostic features of ETP-ALL, the current understanding of genetic aberrations, and its molecular pathogenesis. Furthermore, the role of risk-adapted therapy and allogenic stem cell transplant in alleviating the adverse outcome of ETP-ALL is discussed. Finally, it will highlight potential novel therapies.

\section{DIAGNOSIS AND PITFALL}

\section{Difficulties in Defining ETP-ALL by Immunophenotype}

Coustan-Smith et al. first identified cases of ETP-ALL by comparing the gene expression profile of T-ALL cases with that of earliest thymic precursors (ETPs) in mice. ETP-ALL had a characteristic immunophenotype: CD1a and CD8negative, CD5-negative, or $\operatorname{dim}(<75 \%$ of blasts positive) with one or more stem cell/myeloid markers positive ( $\geq 25 \%$ of blasts positive) (6). This served as the rationale for defining ETP-ALL under the latest WHO 2017 classification: positive intracytoplasmic CD3 expression and CD7 expression, CD1anegative, CD8-negative, negative or dim expression of CD5 ( $<75 \%$ positive), and positive ( $\geq 25 \%$ of blasts population) for at least one stem cell or myeloid antigen, including CD34, HLADR, CD13, CD33, CD117, CD11b, and CD65 (4, 7). CD2 and CD4 may also be positive in ETP-ALL under the latest WHO 2017 classification (4).

Knowledge of the expression of immunological markers during different stages of T-cell development formed the basis of the European Group on Immunological Classification of Leukemia (EGIL) classification of T-ALL (Figure 1) (8). Under the EGIL classification, T-ALL was defined as CD3-positive and TdT-positive and was then further subclassified into T-I (Pro-TALL) to T-IV (Mature T-ALL) according to different immunophenotypic profile (Table 1) $(9,10)$. In the EGIL
TABLE 1 | EGIL Classification of T-ALL (8-10).

\begin{tabular}{lcccccc}
\hline Subtype & \multicolumn{6}{c}{ Pattern of immunophenotypic markers expression } \\
\cline { 2 - 6 } & cCD3 & CD7 & CD2 & CD5 & CD1a & Surface CD3 \\
\hline Pro-T-ALL & + & + & - & - & - & - \\
Pre-T-ALL & + & + & + & + & - & - \\
Cortical T-ALL & + & + & + & + & + & $+/-$ \\
Mature T-ALL & + & + & + & + & - & + \\
\hline
\end{tabular}

classification, there was no specific entity for ETP-ALL but early thymocytes were classified as CDla-negative, CD4negative, and CD8-negative (CD1a-CD4-CD8-) (11). Although the EGIL classification did not present a distinct entity of ETPALL, all cases of T-I ALL and some of the T-II ALL cases could also represent ETP-ALL.

A different scoring system was proposed for diagnosing ETPALL in the study by the Tokyo Children's Cancer Study Group. The group devised a scoring system using a 6-marker or 11marker combination and was validated with a cohort of ETPALL patients from Coustan-Smith et al. (Tables 2, 3) $(6,12)$. The scoring system utilized an extended panel of markers including CD2, surface CD3, CD4, CD10, and CD56 such that it contained an 11-marker combination for scoring. The rationale of the scoring system was that the frequency of CD2, surface CD3, CD4, and CD10 expression was much less frequent from the findings reported by Coustan-Smith et al. (12) Zuurbier et al. evaluated 117 patients with T-ALL and found that the genetic signature of ETP-ALL was best correlated with the following immunophenotype: CD1a-negative, CD4 and CD8-double negative, CD34-positive, and/or CD13/CD33-positive. This immunophenotypic profile had a sensitivity of $77 \%$ and a specificity of $94 \%$ in identifying ETP-ALL. CD5 status was not considered in this study (13). Khogeer et al. included adult ETPALL patients and derived a scoring system utilizing 11 markers. In that scoring system, the expression of surface CD3 (>20\% of blasts) and CD5 ( $>75 \%$ of blasts) contributed “ -2 " marks and a score of $\geq 8$ favored the possibility of an ETP-ALL diagnosis (14).

The expression of CD5 in ETP-ALL is variable and cases with strong CD5 expression are classified as near-ETP-ALL. One study included 69 pediatric and adult patients with the diagnosis of T-ALL. A definite ETP-ALL phenotype was

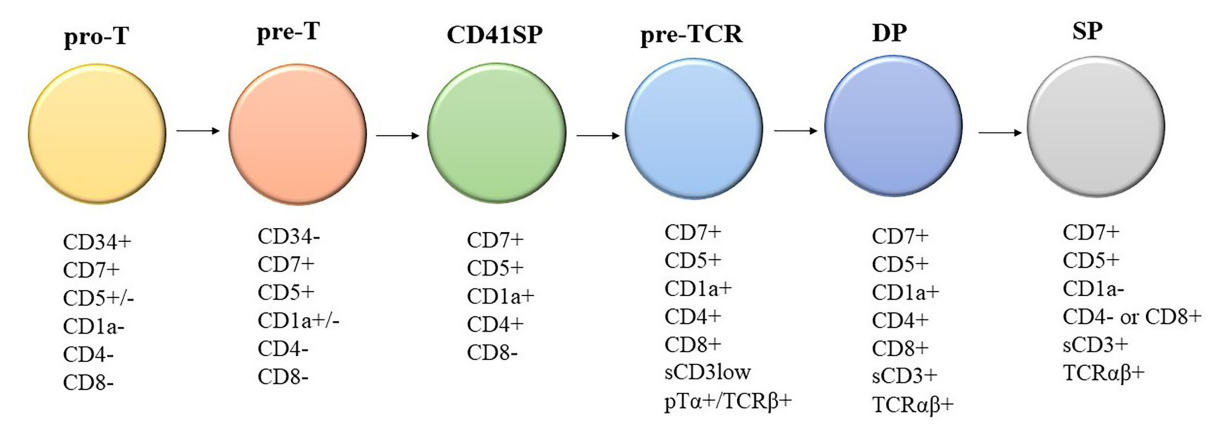

FIGURE 1 | Different stages of T-cell development and their corresponding immunophenotypes: Pro-T, pre-T, immature CD4 single positive (CD4ISP), pre-T-cell receptor (pre-TCR), CD4 and CD8 double positive (DP), and single positive (SP). sCD3: surface CD3; pT $\alpha+/ T C R \beta+$ : Pre-T-cell receptor alpha and TCR beta chain. 
TABLE 2 | Scoring system based on six-marker combination (12).

\begin{tabular}{lcc}
\hline Marker & \multicolumn{1}{c}{} & $\mathbf{+ 1}$ \\
\hline CD5 & $\geq 5 \%$ positive & $<75 \%$ positive \\
CD8 & $\geq 5 \%$ positive & $<5 \%$ positive \\
CD13 & $\geq 25 \%$ positive \\
CD33 & $\geq 25 \%$ positive \\
CD34 & $\geq 25 \%$ positive \\
HLA-DR & $\geq 25 \%$ positive
\end{tabular}

Using a score of 4 or more to define ETP-ALL, the sensitivity and specificity were $77 \%$ and $100 \%$, respectively.

defined by the WHO criteria. The study showed that ETP-ALL associated with more frequent induction failure, and poorer event-free survival (EFS) and overall survival (OS) compared with other subtypes. However, the study found that $91 \%$ of $\mathrm{T}$ ALL cases with immunophenotype CD5+CD1a-CD8- expressed myeloid or stem cell antigens, that is, near-ETP-ALL. The rate of induction failure was significantly higher in this subgroup of TALL, despite a non-significant difference of EFS and OS compared with other subtypes. They concluded that cases of near-ETP-ALL behaved like ETP-ALL (15). However, the study did not perform any genomic profiling to verify the ETP-ALL nature of these cases.

A study by Van Vlierberghe et al. in 2011 analyzed 57 adult TALL patient samples treated with the Eastern Cooperative Oncology Group (ECOG) E2993 protocol. They found that a number of transcriptionally well-defined early immature T-ALL cases with differentiation block of thymocytes at CD4 and CD8 double-negative stage showed strong CD5 positivity (11\% of TALL cases) (16). Morita et al. recruited 171 pediatric and adult patients with T-ALL or T lymphoblastic lymphoma (T-LBL). They found that the cases of ETP-ALL and near-ETP-ALL showed certain similarity in their genetic profile, except that myeloid-associated mutations were particularly enriched in ETPALL. Moreover, the 5-year OS between near-ETP-ALL and nonETP-ALL were similar, with significantly worse 5-year OS in the ETP-ALL subgroup (17). Another study showed that ETP-ALL had a distinct genomic profile with enrichment of LMO2/LYL1 aberrations while near-ETP-ALL and non-ETP-ALL enriched with TAL1 dysregulation (18). These studies showed that both ETP-ALL and near-ETP-ALL share a certain degree of biological similarity and yet may exhibit different genetic profiles and clinical behavior.

TABLE 3 | Scoring system based on 11-marker combination (12).

\begin{tabular}{lcccc}
\hline Marker & $\mathbf{- 2}$ & $\mathbf{- 1}$ & $\mathbf{+ 1}$ & $\mathbf{+ 2}$ \\
\hline CD5 & $\geq 75 \%$ & & & $<75 \%$ positive \\
CD8 & $\geq 5 \%$ positive & & $<5 \%$ positive \\
CD13 & & & $\geq 25 \%$ positive & $\geq 75 \%$ positive \\
CD33 & & & $\geq 25 \%$ positive & $\geq 75 \%$ positive \\
CD34 & & $\geq 25 \%$ positive & $\geq 75 \%$ positive \\
HLA-DR & & $\geq 25 \%$ positive & $\geq 75 \%$ positive \\
CD2 & & & \\
CD3 & & & \\
CD4 & & & & \\
CD10 & & & & \\
CD56 & & & & \\
& & & & \\
\end{tabular}

ETP-ALL had a score $>6$ with a sensitivity of $100 \%$ and a specificity of $94 \%$.
The classification of ETP-ALL by immunophenotyping alone is complicated by the different scoring systems available, technical pitfalls in performing flow cytometry, and variability in interpretating flow cytometry results. Moreover, no single diagnostic criterion is perfect in having both high sensitivity and specificity. Recent studies of the genomic landscape of ETP-ALL provide insights into classification, although no specific genetic aberrations can distinguish ETP-ALL from other subtypes of TALL to date (18). Noronha et al. found that the FBXW7 mutation, $C D K N 2 A / B$ deletion, and STIL-TAL1 fusion were only present in ETP-ALL, and these mutations could be used to differentiate ETPALL and mixed phenotype acute leukemia with the T/myeloid phenotype (19). Recent studies have proposed a classification of acute myeloid leukemia (AML) and ALL by genetic profile clustering. They showed that more than $15 \%$ of leukemia cases could not be reliably classified into either AML or T-ALL and they defined these cases "AML-like T-ALL" and the category was associated with poor prognosis. It is important to note that not all cases of AML-like T-ALL show immature immunophenotype or ETP-ALL phenotype as defined by immunophenotypic criteria (20). Furthermore, single-cell RNA sequencing has demonstrated the expression of signature genes with a spectrum of hematopoietic cells (e.g., mature thymocytes, hemopoietic stem cell, multipotent progenitors, and granulocytic-macrophage progenitors) within the same ETP-ALL cell (21). This suggested that classification of ETPALL by conventional methods including flow immunophenotyping may not be robust enough for treatment planning and disease prognostication.

\section{Technical Considerations for Diagnosing ETP-ALL by Flow Cytometry}

Another challenge of diagnosing ETP-ALL is the presence of significant myeloid differentiation in ETP-ALL, and thus, the diagnosis may be confused with acute undifferentiated leukemia or mixed phenotype acute leukemia with T/myeloid phenotype. The availability of a comprehensive panel of monoclonal antibodies and proper interpretation of flow cytometry results are prerequisites for accurate diagnosis.

The Italian Association of Pediatric Hematology and Oncology-Berlin Frankfurt Munich (AIEOP-BFM) recommend that the flow cytometry panel must include antibodies of all hemopoietic cell lineages to exclude the differential diagnosis of acute undifferentiated leukemia or mixed phenotype acute leukemia with T/myeloid phenotype. Thus, a panel of monoclonal antibodies was recommended by AIEOP-BFM for diagnosing pediatric ALL, and the same principles can be extended to the diagnosis of adult ALL (Table 4) $(4,22)$. To confirm the Tlineage nature of the blast population, the combination of cytoplasmic CD3, CD7, and MPO must be used according to AIEOP-BFM recommendation. The $\mathrm{T}$ lineage nature of blasts is defined by cytoplasmic CD3 and CD7 positivity while MPO is negative (22). The correct interpretation of cytoplasmic CD3 is the key to a correct diagnosis since it defines the $\mathrm{T}$ lineage of blasts. To determine the positivity of cytoplasmic CD3, we should compare staining of a negative internal control sample (e.g., normal B lymphocytes, granulocytes, and monocytes) and positive internal 
TABLE 4 | AlEOP-BFM consensus antibody panel for pediatric ALL (22).

Intracellular antigens

Surface antigens
CD3, CD22, CD79a, cytoplasmic Mu-chain, MPO, Iysozyme (if available)

CD2, CD3, CD5, CD7, CD10, CD19, CD20; CD11b, CD11c, CD13, CD14, CD15, CD33, CD64, CD65, CD117; CD34, CD56, HLA-DR

For T-ALL: CD1a, CD4, CD8, TCR alpha/beta, TCR gamma/delta

For B-ALL: Kappa and lambda light chain

Needs to be combined with CD45.

control (normal T cells). At least a fraction of blasts should have positivity for cytoplasmic CD3, with an intensity that is comparable to that of normal $\mathrm{T}$ cells, in order to consider that blasts are of $\mathrm{T}$ lineage (23). If bone marrow trephine biopsy is available, confirmation of CD3 positivity by immunohistochemical staining on trephine biopsy is preferable (24). A minor proportion of blasts have weak positivity towards cytoplasmic CD3 with an intensity just above the negative control and are not sufficient to conclude the T lineage of blasts, since some cases of AML also have this degree of cytoplasmic CD3 expression. (23) We suggest that diagnostic laboratories should follow the above recommendations for establishing the diagnosis of ETP-ALL from flow cytometry.

In summary, there are two approaches in the diagnosis of ETP-ALL: (1) classification by gene expression profiling or (2) diagnostic criteria by flow cytometry immunophenotyping. For the routine practice of the diagnostic laboratory setting, the first approach is not feasible; thus, we must rely on flow immunophenotyping for diagnosis despite its limitations. The purpose of flow cytometry is not only to diagnose ETP-ALL, but also to establish the diagnosis of acute leukemia among all differential diagnosis of hematological malignancies as well as lineage assignment. Thus, performing immunophenotyping using the comprehensive antibody panel recommended by the AIEOP-BFM is essential for all laboratories to improve diagnostic accuracy (Table 4). The drawback of various scoring systems is that they exclude some of the antibodies recommended by the AIEOP-BFM and the diagnostic sensitivity and specificity are not validated after incorporating the information given by all those antibodies in AIEOP-BFM flow cytometry panel (22). The WHO classification, which is based on the study by Coustain-Smith et al., includes the most extensive panel of markers among all systems of classification discussed above. In addition, the proposed immunophenotypic criteria have been well-validated by gene expression profiling. Thus, we recommend a diagnostic approach (Table 5) based on the backbone of the WHO criteria and knowledge of marker expression of various stages of T-cell development (Figure 1) (8). The definition of CD1a-, CD8-, CD5 negative or dim, surface $\mathrm{CD} 3$, and $\mathrm{T}$-cell receptor expression negative matches the pattern of expression of $\mathrm{T}$ cells earlier than the pro-T-cell stage.

\section{THE CELLULAR ORIGIN OF ETP-ALL AND UNDERLYING MOLECULAR PATHOGENESIS}

Previous studies have identified that the earliest thymic progenitors (ETPs) were derived from multipotent bone marrow progenitor cells, rather than common lymphoid progenitors. They retained $\mathrm{T}$ and myeloid differentiation potential with B-cell differentiation potential lost either prethymically or intrathymically $(25,26)$. The origin of ETPALL has been suggested to be from ETPs since the gene expression profile of ETP-ALL highly resembled that of ETPs (6). Ugal et al. found that by introducing a KRAS mutation and then KMT2A-ENL rearrangement in bone marrow multipotent granulocyte-monocyte-lymphoid progenitors (GMLPs), mice would develop T-ALL (27), which supports the hypothesis of a cellular origin of ETP-ALL from bone marrow multipotent progenitors. A recent study performed on mouse models introduced oncogenic mutations in early lympho-myeloid progenitors, but not in hematopoietic stem cells (HSCs) or multipotent progenitors, and resulted in the development of TALL with the ETP-ALL phenotype (28). The results of these studies demonstrated the cellular origin of ETP-ALL using an in vivo model, which was not inferred from the immunophenotypic and genomic profile of ETP-ALL.

Due to the unique cellular origin of ETP-ALL, its genetic profile differs from that of other subtypes of T-ALL in which the transcription profile was similar to that of HSCs of myeloid leukemia $(6,29)$. Genes encoding transcription factors for development and differentiation, kinase signaling, and epigenetic modifiers are commonly mutated in ETP-ALL. Table 6 summarizes some of the genetic aberrations found in ETP-ALL. NOTCH1 mutation, which is a common mutation in other subtypes of T-ALL (31), is less frequent in ETP-ALL and rather more frequent is the presence of FLT3 and DMNT3A mutations (5). Moreover, several recurrent mutations previously not identified in T-ALL were also identified, including $I L 7 R$, $J A K 3, R U N X 1, E Z H 2$, and EED (29). Mutations in epigenetic regulators (EZH2, PHF6, and SUZ12) were more prevalent in ETP-ALL $(32,33)$. Moreover, gene rearrangement, e.g., $M E F 2 C$ rearrangement and KMT2A rearrangement, is also identified in ETP-ALL $(13,19,32,34)$. The molecular mechanisms of how these mutations lead to leukemogenesis have become clearer with recent pre-clinical and clinical studies.

\section{Mutations in Transcription Factors and Leukemogenesis of ETP-ALL}

$L M O 2$ is a transcription factor belonging to the LIM-only class. Expression of LMO2 in thymocytes increases transcription of HSC-associated genes and repression of genes responsible for Tcell development (35). Besides LMO2 overexpression, LYL1 is needed to promote abnormal self-renewal and induce the differentiation block in thymocytes and are frequently coexpressed in ETP-ALL (36). Overexpression of LMO2 and 
TABLE 5 | Suggested diagnostic criteria for ETP-ALL.

ALL cases must be positive for cytoplasmic $C D 3$ positive and $C D 7$ plus the following:

Mandatory criteria (All of the criteria must be present):

1. CD1a negative
2. CD8 negative
3. Surface CD3 negative
4. TCR alpha/beta and TCR gamma/delta negative
5. CD5 negative or dim (<75\% of blasts positive)
6. One or more stem cell/myeloid antigens as stated in WHO classification (CD34, HLA-DR, CD13, CD33,
CD117, CD11b, and CD65)

Positivity of these markers do not exclude the diagnosis CD2, CD4, CD10

of ETP-ALL

LYL1 was present in $36.8 \%$ of ETP-ALL in one study (32). $B C L 11 B$ is another transcription factor that is expressed in early $\mathrm{T}$ cells and an increase in its expression is associated with irreversible $\mathrm{T}$-cell lineage commitment and differentiation of $\mathrm{T}$ cells into CD4 and CD8 double-positive cells $(37,38)$. Mutation of $B C L 11 B$ causing its under-expression was reported in ETPALL $(29,32,39)$. RUNX1 is important in the regulation of thymocyte differentiation and a loss-of-function mutation/ deletion of RUNX1 leads to maturation arrest of thymocytes (40). GATA3 was shown to be important for the development of ETPs and differentiation to mature T cells (41). Approximately $33 \%$ of adult ETP-ALL lack GATA3 expression, which is mainly due to hypermethylation (42).

\section{Genetic Rearrangement and Leukemogenesis in ETP-ALL}

$M E F 2 C$ rearrangement or rearrangement involving $M E F 2 C$ related cofactors accounts for approximately half of ETP-ALL cases (43). $M E F 2 C$ rearrangement results in upregulation of $M E F 2 C$ expression, which leads to differentiation block of early thymocytes by upregulating LMO2 and LYL1. Additional genetic aberrations in $R A S$ and $M Y C$ promote the development of the leukemic phenotype (34). KMT2A rearrangement results in the upregulation of HOXA-related genes in T-ALL (44), which was found to cause differentiation block of progenitor cells and promote the leukemic phenotype (45). Furthermore, the overexpression of HOXA in adult T-ALL was shown to be associated with the ETP-ALL phenotype. ETP-ALL with HOXA overexpression was also associated with poor survival and increased relapse rate (46). Introducing KMT2A-ELN fusion in bone marrow progenitor caused differentiation block of thymocytes and the addition of RAS mutation promoted leukemic phenotype (27).

\section{Activating IL7R Mutations and Leukemogenesis in ETP-ALL}

IL7R mutations are common in adult ETP-ALL (45\% of ETPALL) and are associated with slow response to chemotherapy. IL7R mutations also constitute $8 \%$ of pediatric ETP-ALL $(29,47)$. Moreover, mutations in the $I L 7 R$ pathway were also associated with PRC2 mutations in T-ALL (48).

$I L 7 R$ encodes the IL7 receptor alpha chain, which is important for early lymphoid maturation (49). IL7R mutations trigger autonomous homodimerization with activation of the receptor and subsequent phosphorylation of STAT5. It results in dysregulation of various pathways, such as the upregulation of $B C L 2$ expression, downregulation of cyclin-dependent inhibitor p27kip1, and hyperactivation of the PI3K/Akt/mTOR and JAK/ STAT pathways, with subsequent progression to leukemic phenotype $(29,47,50-55)$. A recent study showed that IL7R mutations upregulate $L M O 2$ expression while downregulating $B C L 11 B$ expression and lead to a differentiation block in thymocytes. Upregulation of myeloid-associated genes was also observed in thymocytes due to $I L 7 R$ mutations (50). The above studies indicate that mechanisms involved in leukemogenesis associated with $I L 7 R$ mutation are due to differentiation block of thymocytes as well as dysregulation of pathway affecting growth and apoptosis (Figure 2).

\section{Mutations in Epigenetic Regulators in Leukemogenesis of ETP-ALL}

Polycomb repression complex 2 (PRC2) is a protein complex regulating histone modifications and expression of developmental genes. EZH2 is a component of PRC2 that carries a SET domain involved in methylating lysine 27 of the histone 3 tail (H3K27me3). This histone modification recruits PRC1, which then condenses the chromosome and suppresses gene transcription (Figure 3) (56). Mutations in PRC2 components occur in up to $48 \%$ of pediatric ETP-ALL with the most common mutation being a loss-of-function mutation in EZH2, followed by SUZ12 and EED (29).

Mice transplanted with $C D K N 2 A^{-/-} / N R A S$ Q61K/EZH2 $2^{\Delta / \Delta}$ mutated lineage-negative, SCA-positive, and c-Kit-positive (LSK) cells generate acute leukemia with the ETP-ALL phenotype. The homozygous loss of EZH2 resulted in an increase in the transcription of genes relating to stem-cell and early-progenitor-cell programming with a differentiation block at the ETP stage. This results in hyperactivation of the JAK/ STAT signaling pathway via IL6RA and STAT3 upregulation (Figure 4). HOXA is upregulated as well (57). Similar findings resulting from $E Z H 2$ knockout were found by implanting

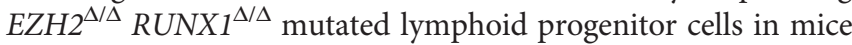
in another study. However, the FLT3-ITD mutation was needed for progression to acute leukemia with ETP-ALL phenotype. The addition of FLT3-ITD mutation was also associated with upregulation of genes for RAS signaling and IL7R (28). Lossof-function mutations in EZH2 also associate with DNA hypermethylation. The transcription of various genes, for 
TABLE 6 | Example of genetic aberrations in $\operatorname{ETP-ALL~}(18,29,30)$.

\begin{tabular}{ll}
\hline Gene & \multicolumn{1}{c}{ Type of aberration } \\
\hline Transcription factors & \\
ETV6 & Inactivating mutations/deletions \\
GATA3 & Inactivating mutations/deletions \\
HOXA & Chromosomal \\
& rearrangements/inversions/overexpression \\
LMO2 & Chromosomal \\
& rearrangement/deletions/overexpression \\
RUNX1 & Inactivating mutations/deletions \\
WT1 & Inactivating mutations/deletions \\
Signaling pathway & \\
FLT3 & Activating mutations/internal-tandem repeat \\
JAK1 & Activating mutations \\
JAK3 & Activating mutations \\
IL7R & Activating mutations \\
KRAS & Activating mutations \\
NRAS & Activating mutations \\
Epigenetic modifiers & \\
DNMT3A & Inactivating mutations \\
EED & Inactivating mutations/deletions \\
EZH2 & Inactivating mutations/deletions \\
PHF6 & Inactivating mutations/deletions \\
SUZ12 & Inactivating mutations/deletions \\
Genetic rearrangement & \\
STIL-TAL1 fusion & \\
MEF2C rearrangement & \\
KMT2A rearrangement & \\
NUP98 rearrangement & \\
\hline & \\
\hline
\end{tabular}

example, RUNX1, was reduced due to DNA hypermethylation (58). Further studies are required to elucidate the role of DNA hypermethylation in leukemogenesis.

In summary, a loss-of-function mutation of EZH2 in ETP leads to maturation arrest at the ETP stage by modulating gene expression via the reduction of histone methylation and DNA hypermethylation. However, progression to acute leukemia with the ETP-ALL phenotype requires acquisition of other driver mutations, such as FLT3-ITD and NRAS, that lead to dysregulation of pathways regulating cellular proliferation and apoptosis (Figure 5) $(28,57,58)$. This provides mechanistic basis for designing targeted therapy to reverse differentiation block and inhibit driver mutations as a possible synergistic treatment regimen.

\section{CLINICAL MANAGEMENT OF ETP-ALL}

Conventional intensive chemotherapy remains the mainstay of treatment for ETP-ALL and poor prognosis was reported by Coustan-Smith et al. compared with non-ETP-ALL (6). However, the prognostic impact of ETP-ALL phenotype alone is controversial from recent studies. Table 7 summarizes the findings of these clinical studies.

\section{Results of Studies Involving Pediatric Patients}

A total of 47 pediatric T-ALL patients from the Children's Oncology Group (COG) 09404 and the Dana-Farber Cancer Institute (DFCI) 00-01 study were included in a study, which showed that the absence of the biallelic T-cell receptor (TCR) gamma deletion was strongly associated with induction failure. This subgroup of T-ALL conferred significantly worse EFS and OS than the other subgroup of T-ALL. Among the 40 patients showing biallelic TCR gamma deletion with gene expression data available, 14 presented features consistent with ETP-ALL. The ETP-ALL phenotype showed similar effects on EFS and OS as

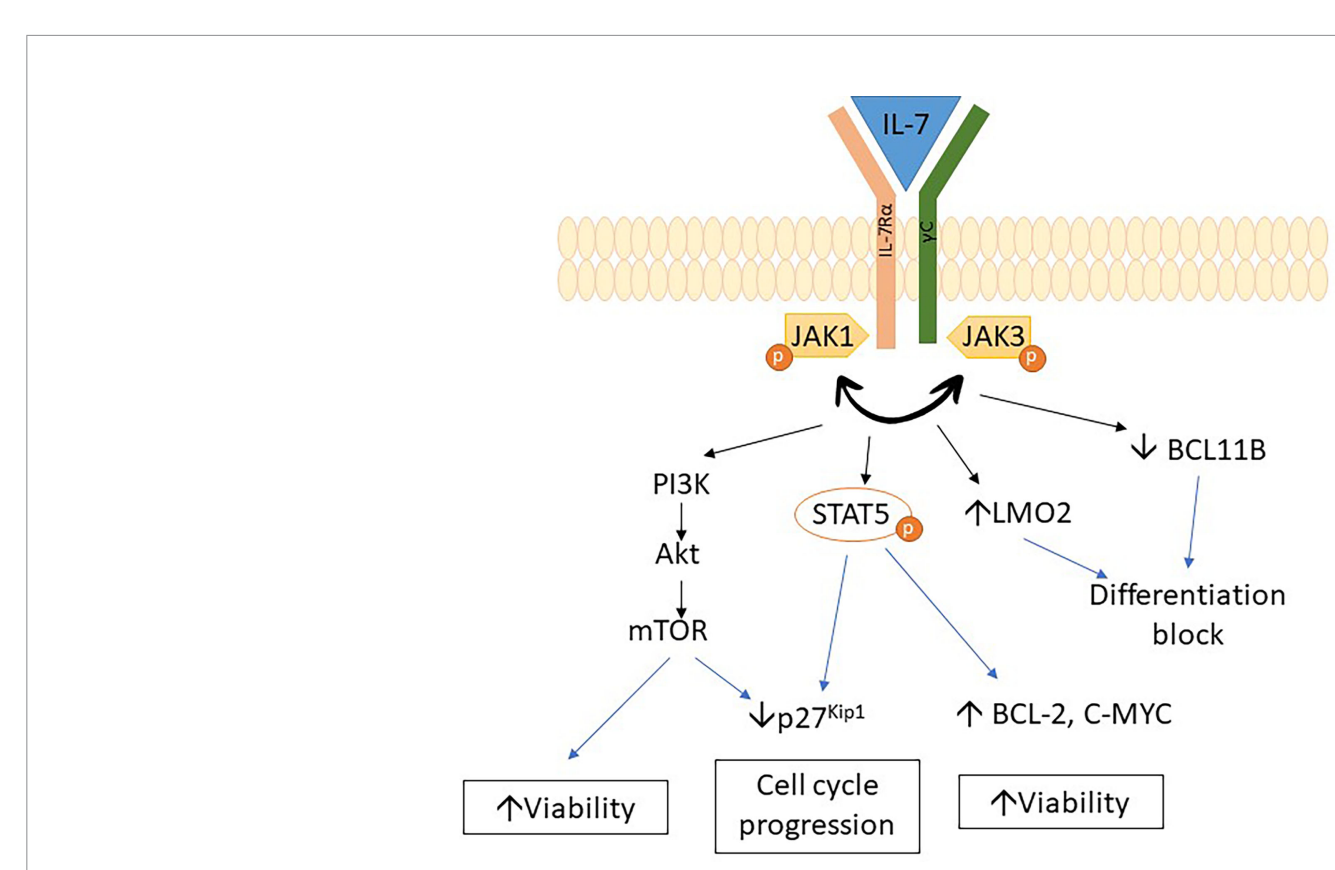

FIGURE 2 | Schematic diagram representing the mechanism of leukemogenesis of IL7R mutations. 


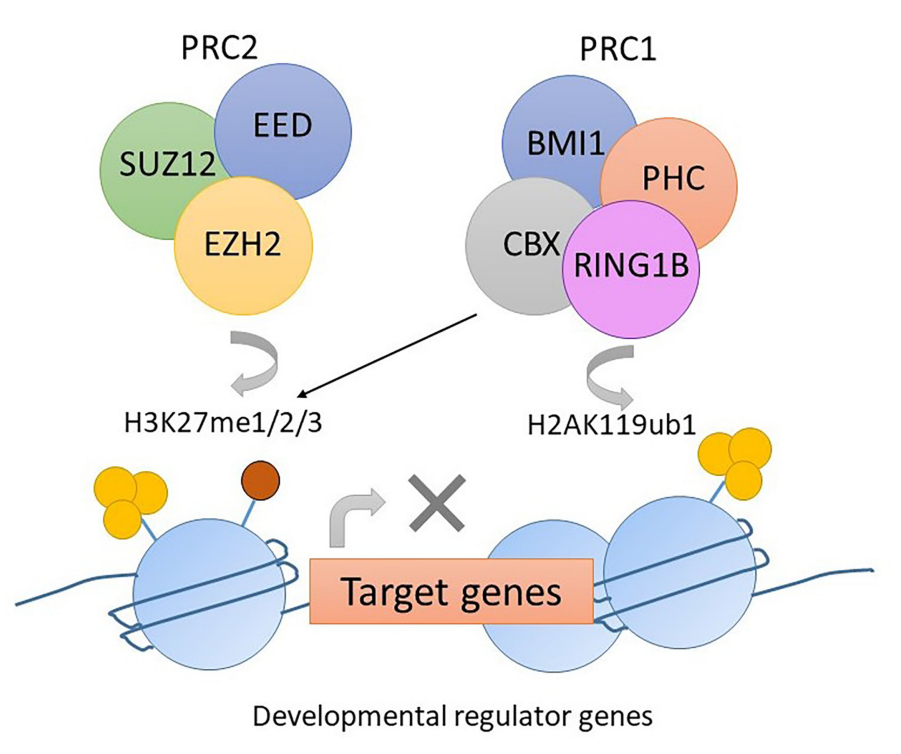

FIGURE 3 | The function of PRC2 complex in normal hemopoiesis. EZH2 mediates the methylation of lysine 27 of histone 3 tail (H3K27me3). The histone modification H3K27me3 recruits PRC1. CBX in PRC1 mediates mono-ubiquitylation of lysine 119 of histone 2A (H2AK119ub). Gene transcription is suppressed due to histone modification.

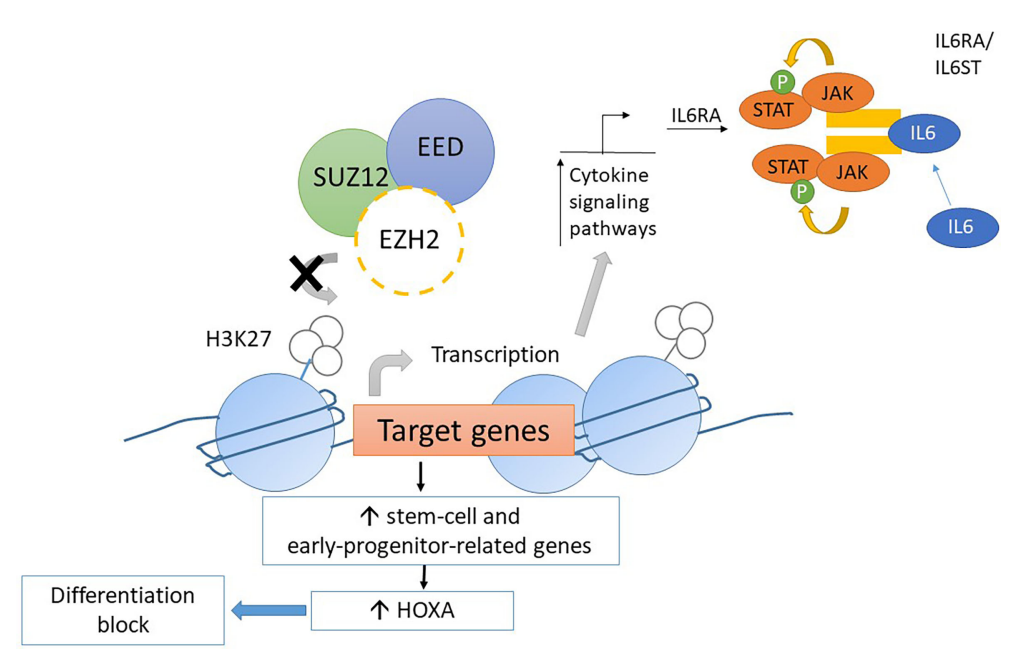

FIGURE 4 | Mechanism of leukemogenesis due to loss-of-function mutation in EZH2. Loss-of-function mutations in EZH2 increase transcription of stem-cell and early-progenitor related genes including HOXA. It results into differentiation block of thymocytes. Moreover, the transcription of IL6RA is increased due to loss-offunction EZH2 mutations. Thus, the expression of IL6 receptor is increased and causes hyperresponsiveness to IL6 which results into hyperactivation of STAT3.

biallelic TCR gamma deletion. However, only one patient from the above cohort exhibited an immunophenotype consistent with ETP-ALL, which highlighted that flow immunophenotyping had presented limitations in diagnosing ETP-ALL as mentioned above (70).

The Tokyo Children's Cancer Study Group (TCCSG) study L99-15 included 91 Japanese patients aged 1-18 years with a diagnosis of T-ALL. Among these, five patients met the diagnostic criteria of ETP-ALL. They were treated with a pediatric protocol described by Manabe et al. (71) The patients were stratified into three risk groups according to blast count in the peripheral blood after 7 days of prednisolone therapy and allogenic hemopoietic stem cell transplant was offered to those in the high-risk group. In the cohort of patients with ETP-ALL, the EFS was significantly worse than in other subtypes ( $40 \%$ vs. $70 \%$ over 4 years). There was no statistically significant difference in OS between the ETP-ALL and other subtypes. Allogenic HSC transplant might also play a role in alleviating the adverse 


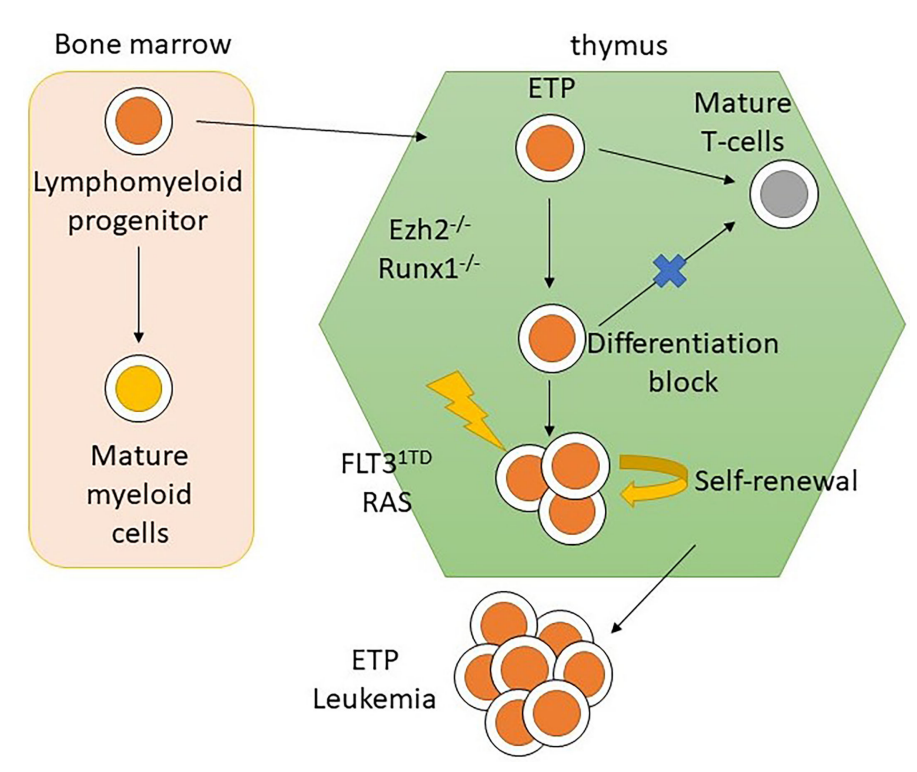

FIGURE 5 | The role of mutation in EZH2, RUNX1, RAS, and FLT3-ITD in leukemogenesis of ETP-ALL.

outcomes of ETP-ALL patients from that study (12). However, the main weakness of the study was the limited number of ETPALL patients recruited.

Sayed et al. recruited 103 pediatric patients (aged 1-18 years) with T-ALL from various Arab centers. Among them, 16.5\% exhibited the ETP-ALL phenotype and most were treated with St Jude Total Therapy Study XIII for high-risk ALL protocol. There was a trend for a higher rate of induction failure in ETP-ALL versus non-ETP-ALL patients $(10 \%$ vs. $7 \%, p=0.679)$. The OS and disease-free survival (DFS) were not statistically different between ETP-ALL and non-ETP-ALL. The study indicated that the adverse outcome of ETP-ALL could be overcome by riskadapted treatment intensification. However, the power of this study was limited by the small sample size of ETP-ALL patients (61).

A retrospective study included 49 patients treated with the AIEOP-BFM protocol aged 1-18 years old with a diagnosis of ETP-ALL. The AIEOP-BFM protocol is composed of three blocks of polychemotherapy after phase $1 \mathrm{~B}$ intensification in ALL high-risk group patients, and as defined by poor day 7 prednisolone response, complete remission was not achieved after phase $1 \mathrm{~A}$ or MRD level $\geq 5 \times 10^{-4}$ after day 78 of treatment. Despite the higher number of patients with blasts $\geq 10 \%$ at day 15 of treatment, poor prednisolone response, complete remission not achieved after phase 1A of therapy, as well as a significant proportion of patients with a MRD level above $5 \times 10^{-4}$ after day 33 (85\% of patients) and day 78 (20\% of patients) of treatment, the 3 -year EFS rate was $86 \%$, and it was not significantly different from other subtypes of T-ALL. (68) Thus, the outcome of ETPALL improved with treatment intensification in that study.

Pediatric patients from the AIEOP-BFM ALL 2000 trial diagnosed with T-ALL were treated with multi-block chemotherapy and MRD-directed regimens. The study showed that the ETP-ALL phenotype did not affect the EFS and OS significantly. However, the study did find a negative prognostic impact in terms of inferior EFS and OS for CD56-positive TALL. Approximately $30 \%$ of ETP-ALL patients had CD56 positivity, while only $5.1 \%$ of non-ETP-ALL expressed CD56 (64). Similarly, specific genetic markers, e.g., NOTCH1 mutation, were associated with the patient's outcome. Noronha et al. found that the presence of NOTCH1 mutation conferred a favorable prognosis in ETP-ALL with significantly better OS for pediatric patients (19).

A study including a large cohort of 464 pediatric patients with T-ALL showed that ETP-ALL was strongly associated with positive MRD after day 33 and day 78 of treatment, in patients belonging to the MRD high-risk group, and this group also presented a higher incidence of relapse (7-year cumulative incidence of relapse: $44.7 \%$ ). Allogenic HSC transplant reduced the risk of relapse in these patients compared with chemotherapy alone (72).

\section{Studies Involving Both Pediatric and Adult Patients}

A study by Jain et al. included 111 patients from the MD Anderson Cancer Center with a diagnosis of T-ALL/ lymphoblastic lymphoma. Of these, 15 patients fulfilled the criteria of ETP-ALL and 4 patients fulfilled the criteria of T lymphoblastic lymphoma with the ETP-ALL phenotype. In that study, patients were treated with either the hyper-CVAD +/nelarabine or the augmented Berlin-Frankfurt-Münster (BFM) regimen. The study showed that the ETP-ALL phenotype was associated with inferior outcome than other subtypes of T-ALL. The median OS was 20 months in ETP-ALL versus non-reached in other T-ALL subtypes. Although the status of MRD negativity did not affect the outcome of ETP-ALL, the number of patients 
TABLE 7 | Clinical studies of evaluating the outcome of ETP-ALL.

\begin{tabular}{|c|c|c|c|c|c|c|}
\hline Study & $\begin{array}{c}\text { Age of } \\
\text { patients }\end{array}$ & $\begin{array}{l}\text { Number of patients } \\
\text { with ETP-ALL }\end{array}$ & Study details & Nature of study & Result & Remarks \\
\hline $\begin{array}{l}\text { Coustan- } \\
\text { Smith } \\
\text { et al. (6) }\end{array}$ & $\begin{array}{l}0.5-18 \\
\text { years }\end{array}$ & $\begin{array}{l}239 \text { with T-ALL, } 30 \text { had } \\
\text { ETP-ALL signature }\end{array}$ & $\begin{array}{l}\text { Compared } \\
\text { outcome between ETP- } \\
\text { ALL and non-ALL treated } \\
\text { with standard } \\
\text { chemotherapy }\end{array}$ & Retrospective & $\begin{array}{l}10-\text { year OS 19\% vs. } 85 \% \text {, } \\
10 \text {-year EFS 22\% vs. } \\
69 \% \text { ( } p<0.0001) \text {, for } \\
\text { ETP-ALL vs. non-ETP- } \\
\text { ALL }\end{array}$ & $\mathrm{Nil}$ \\
\hline $\begin{array}{l}\text { Inukai } \\
\text { et al. (12) }\end{array}$ & $\begin{array}{l}1-18 \\
\text { years }\end{array}$ & 5 ETP-ALL patients & $\begin{array}{l}\text { Compared outcome } \\
\text { between ETP-ALL and } \\
\text { non-ALL treated with } \\
\text { pediatric protocol }\end{array}$ & Retrospective & $\begin{array}{l}\text { 1. 4-year EFS } 40 \% \text { (ETP- } \\
\text { ALL) vs. } 70 \% \text { (non-ETP- } \\
\text { ALL), } p=0.014 \\
\text { 2. Overall survival not } \\
\text { statistically different }\end{array}$ & $\begin{array}{l}\text { Limited number of patients with } \\
\text { ETP-ALL }\end{array}$ \\
\hline $\begin{array}{l}\text { Allen et al. } \\
\text { (59) }\end{array}$ & $\begin{array}{l}1-81 \\
\text { years }\end{array}$ & 7 ETP-ALL patients & $\begin{array}{l}\text { Compared outcome of } \\
\text { ETP-ALL and non-ETP- } \\
\text { ALL treated with } \\
\text { conventional } \\
\text { chemotherapy }\end{array}$ & Retrospective & $\begin{array}{l}\text { 1. Significantly higher } \\
\text { relapse rates in pediatric } \\
\text { ETP-ALL (HR }=11.63 \text {, } \\
p=0.025) \\
2 . \text { No difference in event- } \\
\text { free and overall survival in } \\
\text { all age group }\end{array}$ & $\begin{array}{l}\text { 1. Limited sample size } \\
\text { 2. Heterogeneity of treatment } \\
\text { regimen }\end{array}$ \\
\hline $\begin{array}{l}\text { Patrick } \\
\text { et al. (60) }\end{array}$ & $\begin{array}{l}1-24 \\
\text { years }\end{array}$ & $\begin{array}{l}35 \text { patients with ETP- } \\
\text { ALL }\end{array}$ & $\begin{array}{l}\text { Compare outcome of } \\
\text { ETP-ALL and non-ETP- } \\
\text { ALL treated with UKALL } \\
2003 \text { protocol }\end{array}$ & $\begin{array}{l}\text { Review of data from } \\
\text { randomized control trial } \\
\text { (UKALL } 2003 \text { trial) }\end{array}$ & $\begin{array}{l}\text { Apparently inferior 5-year } \\
\text { EFS and OS for ETP-ALL } \\
\text { (76.7\% vs. } 84.6 \%, 82.4 \% \\
\text { vs. } 90.9 \% \text { ) but not } \\
\text { statistically significant }\end{array}$ & $\begin{array}{l}\text { Adverse prognostic features of } \\
\text { ETP-ALL might overcome by } \\
\text { risk-adapted therapy with } \\
\text { treatment intensification }\end{array}$ \\
\hline $\begin{array}{l}\text { Sayed } \\
\text { et al. (61) }\end{array}$ & $\begin{array}{l}1-18 \\
\text { years }\end{array}$ & $\begin{array}{l}103 \text { patients with T-ALL, } \\
16.5 \% \text { of them were } \\
\text { ETP-ALL }\end{array}$ & $\begin{array}{l}\text { Compared outcome of } \\
\text { ETP-ALL vs. non-ETP-ALL } \\
\text { treated with different } \\
\text { protocol }\end{array}$ & Retrospective & $\begin{array}{l}\text { Patients treated with the } \\
\text { Total Therapy Study XIII } \\
\text { protocol had a non- } \\
\text { statistically significant } \\
\text { inferior outcome for ETP: } \\
70.8 \% \text { vs. } 76.6 \% \text { ( } p= \\
0.67 \text { ) }\end{array}$ & $\begin{array}{l}\text { Adverse prognosis of ETP-ALL } \\
\text { might be overcome by risk- } \\
\text { adapted treatment intensification }\end{array}$ \\
\hline $\begin{array}{l}\text { Brammer } \\
\text { et al. (63) }\end{array}$ & $\begin{array}{l}2-72 \\
\text { years }\end{array}$ & $\begin{array}{l}16 \text { patients with ETP- } \\
\text { ALL }\end{array}$ & $\begin{array}{l}\text { Analysis of outcome of } \\
\text { different T-ALL subtypes } \\
\text { and MRD status after } \\
\text { allogenic stem cell } \\
\text { transplant }\end{array}$ & Retrospective & $\begin{array}{l}\text { Not statistically different in } \\
3 \text {-year OS after allogenic } \\
\text { SCT in CR1 ( } 47 \% \text { vs. } \\
65 \%, p=0.5 \text { ) }\end{array}$ & $\begin{array}{l}\text { 1. Allogenic SCT might overcome } \\
\text { adverse prognosis of ETP-ALL } \\
\text { 2. Limited sample size }\end{array}$ \\
\hline $\begin{array}{l}\text { S. } \\
\text { Fuhrmann } \\
\text { et al (64) }\end{array}$ & $\begin{array}{l}1-18 \\
\text { years }\end{array}$ & $\begin{array}{l}493 \text { T-ALL patients in } \\
\text { total, } 33 \text { patients with } \\
\text { ETP-ALL }\end{array}$ & $\begin{array}{l}\text { Analysis of outcome of } \\
\text { CD56 expression status in } \\
\text { T-ALL from ALL-BFM } \\
2000 \text { trial }\end{array}$ & $\begin{array}{l}\text { Analysis of data from } \\
\text { prospective trial } \\
\text { (AlEOP-BFM ALL } 2000 \\
\text { study) }\end{array}$ & $\begin{array}{l}\text { 1. Not statistically } \\
\text { significantly different in } \\
\text { event-free survival } \\
\text { 2. CD56 expression had } \\
\text { inferior } 5 \text {-year event-free } \\
\text { survival }(60 \% \text { vs. } 82 \%, p \\
=0.002 \%) \text { and } 5 \text {-year } \\
\text { overall survival (60\% vs. } \\
85 \%, p=0.003 \%)\end{array}$ & $\begin{array}{l}\text { 1. } 30 \% \text { of ETP-ALL express } \\
\text { CD56 vs. } 5.1 \% \text { in non-ETP-ALL } \\
\text { 2. MRD-directed therapy } \\
\text { improved outcome of ETP-ALL }\end{array}$ \\
\hline $\begin{array}{l}\text { Dunsmore } \\
\text { et al (65) }\end{array}$ & $\begin{array}{l}1-31 \\
\text { years }\end{array}$ & $\begin{array}{l}\text { 1,596 patients with } \mathrm{T}- \\
\text { ALL, }\end{array}$ & $\begin{array}{l}\text { Phase } 3 \text { RCT of nelarabine } \\
\text { randomization in addition } \\
\text { to escalating-dose } \\
\text { methotrexate (MTX) plus }\end{array}$ & $\begin{array}{l}\text { Randomized control } \\
\text { trial }\end{array}$ & $\begin{array}{l}\text { 1. No statistically } \\
\text { significant impact on DFS } \\
\text { (hazard ratio, 0.99; } 95 \% \\
\mathrm{Cl}, 0.59 \text { to } 1.67 \text {; P } 5.981 \text {; } \\
\mathrm{p}=0.981 \text { ). }\end{array}$ & $\begin{array}{l}92 \text { patients with ETP-ALL taken } \\
\text { off from the study protocol. } \\
\text { Among them, } 28 \text { received } \\
\text { allogenic hemopoietic stem cell }\end{array}$ \\
\hline
\end{tabular}


TABLE 7 | Continued

\begin{tabular}{|c|c|c|c|c|c|c|}
\hline Study & $\begin{array}{c}\text { Age of } \\
\text { patients }\end{array}$ & $\begin{array}{l}\text { Number of patients } \\
\text { with ETP-ALL }\end{array}$ & Study details & Nature of study & Result & Remarks \\
\hline & & & $\begin{array}{l}\text { pegaspargase (C-MTX) or } \\
\text { high dose methotrexate }\end{array}$ & & $\begin{array}{l}\text { 2. No significant difference } \\
\text { in 5-year event-free } \\
\text { survival ( } 87 \% \text { vs. } 86.9 \%) \\
\text { and overall survival (93\% } \\
\text { vs. 92\%) between ETP- } \\
\text { ALL vs. non-ETP-ALL. }\end{array}$ & $\begin{array}{l}\text { transplant. This might contribute } \\
\text { to improve outcome of ETP-ALL }\end{array}$ \\
\hline $\begin{array}{l}\text { Burns } \\
\text { et al. (66) }\end{array}$ & $\begin{array}{l}1-21 \\
\text { years }\end{array}$ & $\begin{array}{l}123 \text { T-ALL patients, } 21 \\
\text { patients had ETP-ALL }\end{array}$ & $\begin{array}{l}\text { Analysis of patients } \\
\text { enrolled into DFCl 05-001 } \\
\text { and DFCl 11-001 trial and } \\
\text { identify prognostic factors } \\
\text { of T-ALL }\end{array}$ & $\begin{array}{l}\text { Analysis of data from } \\
\text { phase III randomized } \\
\text { controlled trials (DFCl } \\
05-001 \text { and DFCl 11- } \\
001 \text { trial) }\end{array}$ & $\begin{array}{l}\text { 1. ETP-ALL associated } \\
\text { with higher rate of } \\
\text { induction failure ( } 33 \% \text { vs. } \\
5 \%, p=0.008) \\
\text { 2. Inferior } 5 \text {-year event- } \\
\text { free survival for ETP-All } \\
\text { (54\% vs. } 87 \%, p=0.006) \\
\text { 3. Not statistically different } \\
\text { in } 5 \text {-year overall survival } \\
(85 \% \text { vs. } 92 \%, p=0.31) \text {. }\end{array}$ & $\begin{array}{l}\text { 1. Adverse prognosis of ETP-ALL } \\
\text { could be overcome by treating } \\
\text { with high-risk ALL regimen. }\end{array}$ \\
\hline $\begin{array}{l}\text { Morita } \\
\text { et al. (17) }\end{array}$ & $\begin{array}{l}13-78 \\
\text { years, } \\
\text { median } \\
\text { age } 30 \\
\text { years }\end{array}$ & $\begin{array}{l}171 \mathrm{~T}-\mathrm{ALL} \text { patients in } \\
\text { total, } 21 \text { of them were } \\
\text { ETP-ALL }\end{array}$ & $\begin{array}{l}\text { Analysis of outcome of } \\
\text { newly diagnosed near- } \\
\text { ETP-ALL upon treatment } \\
\text { of frontline chemotherapy } \\
\text { with or without allo-SCT } \\
\text { and effect of nelarabine }\end{array}$ & Retrospective & $\begin{array}{l}\text { 1. CR rate of ETP was } \\
\text { similar vs. near-ETP-ALL } \\
\text { and non-ETP-ALL ( } 83 \text { vs. } \\
79 \% \text { vs. } 91 \% \text { ) } \\
\text { 2. Inferior } 5 \text {-year event- } \\
\text { free survival of ETP-ALL } \\
\text { vs. non-ETP-ALL ( } 24 \% \text { vs. } \\
60 \%, p<0.001 \text { ) and } 5 \text { - } \\
\text { year overall survival }(32 \% \\
\text { vs. } 63 \%, p<0.001) \\
\text { 3. Allo-SCT improved 5- } \\
\text { year EFS (36\% vs. } 18 \%, p \\
=0.03) \text {. }\end{array}$ & $\begin{array}{l}1 \text {.Allo-HSCT had a trend of } \\
\text { better } 5 \text {-year overall survival in } \\
\text { ETP-ALL though not statistically } \\
\text { significant ( } 36 \% \text { vs. } 29 \%, p= \\
0.218 \text { ) } \\
\text { 2. Allo-HSCT might improve } \\
\text { outcome of ETP-ALL }\end{array}$ \\
\hline $\begin{array}{l}\text { Genesca } \\
\text { et al. (67) }\end{array}$ & $\begin{array}{l}\text { Adult T- } \\
\text { ALL, } \\
\text { mean } \\
\text { age } 33.5 \\
\text { years }\end{array}$ & $\begin{array}{l}185 \text { T-ALL patients in } \\
\text { total, } 34 \text { of them were } \\
\text { ETP-ALL }\end{array}$ & $\begin{array}{l}\text { Analysis of clinic-biological, } \\
\text { outcome, and prognostic } \\
\text { features of PETHEMA and } \\
\text { ALL-HR-2003 trials }\end{array}$ & Retrospective & $\begin{array}{l}\text { 1. ETP-ALL significantly } \\
\text { lower CR rate upon } \\
\text { induction ( } 77 \% \text { vs. } 94 \% \text {, } \\
p=0.005) \\
\text { 2. ETP-ALL had lower } \\
\text { MRD negative rate after } \\
\text { day } 35 \text { induction ( } 35 \% \text { vs. } \\
82 \%, p<0.001, \mathrm{MRD}< \\
0.1 \% \text { as cutoff) } \\
\text { 3. Inferior overall survival } \\
\text { at } 4 \text {-year for ETP-ALL } \\
\text { (36\% vs. } 49 \%, p=0.037 \text { ) }\end{array}$ & $\begin{array}{l}1 . \text { Higher rate of induction failure } \\
\text { and slow MRD clearance for } \\
\text { ETP-ALL } \\
\text { 2. The overall survival for patients } \\
\text { with allo-SCT was lower in } \\
\text { PETHEMA }\end{array}$ \\
\hline $\begin{array}{l}\text { Conter } \\
\text { et al. (68) }\end{array}$ & $\begin{array}{l}1-18 \\
\text { years }\end{array}$ & $\begin{array}{l}139 \text { treated with AIEOP } \\
\text { R2006 study, } 16 \text { of them } \\
\text { ETP-ALL. } 201 \text { T-ALL } \\
\text { patients from AIEOP- } \\
\text { BFM } 2009 \text { study, } 33 \text { of } \\
\text { them were ETP-ALL }\end{array}$ & $\begin{array}{l}\text { Analysis outcome of ETP- } \\
\text { ALL patients treated with } \\
\text { AIEOP-BFM protocol }\end{array}$ & Retrospective & $\begin{array}{l}\text { 1. High rate of MRD } \\
\text { positivity (cutoff } 5 \times 10^{-4} \text { ): } \\
85 \% \text { at day } 33 \text { and day } \\
78 \mathrm{~A} \\
2 \text {.AlEOP-ALL R2006 } \\
\text { study: } 5 \text {-year event-free } \\
\text { and overall survival } \\
\text { (56.3\% and } 55.6 \% \text {, } \\
\text { respectively) } \\
\text { 3. AlEOP-BFM ALL } 2009 \\
\text { study: 3-year event-free } \\
\text { and overall survival } \\
\text { (86.2\%) }\end{array}$ & $\begin{array}{l}\text { 1. Slow marrow response and } \\
\text { MRD response for ETP-ALL } \\
\text { 2. Outcome of AIEOP-BFM ALL } \\
2009 \text { study not statistically } \\
\text { different from non-ETP-ALL } \\
3 \text {.More patients assigned to } \\
\text { high-risk treatment protocol in } \\
\text { AlEOP-BFM ALL } 2009 \text { study due } \\
\text { to positive MRD } \\
4 \text {.Improve outcome of ETP-ALL } \\
\text { after treatment intensification }\end{array}$ \\
\hline $\begin{array}{l}\text { P. Quist- } \\
\text { Paulsen } \\
\text { et al. (69) }\end{array}$ & $\begin{array}{l}1-45 \\
\text { years }\end{array}$ & $\begin{array}{l}\text { A total of } 278 \mathrm{~T}-\mathrm{ALL} \\
\text { patients, } 37 \text { of them } \\
\text { were ETP-ALL }\end{array}$ & $\begin{array}{l}\text { Analysis of results of both } \\
\text { pediatric and adult } \\
\text { patients with ALL treated } \\
\text { with NOPHO ALL 2008, a } \\
\text { pediatric-inspired protocol }\end{array}$ & $\begin{array}{l}\text { Prospective study of } \\
\text { patients treated with } \\
\text { NOPHO ALL } 2008 \\
\text { protocol }\end{array}$ & $\begin{array}{l}\text { 1. Higher MRD at day } 29 \\
(0.3 \% \text { vs. } 0.04 \%, p= \\
0.001) \\
\text { 2. Not statistically } \\
\text { significantly different in } \\
\text { relapse risk and overall } \\
\text { survival }\end{array}$ & $\begin{array}{l}\text { Most patients assigned to high- } \\
\text { risk protocol or allo-SCT due to } \\
\text { poor early MRD response }\end{array}$ \\
\hline
\end{tabular}

EFS, Event-free survival; OS, Overall survival; HR, Hazard ratio; CR, Complete remission; RCT, Randomized-controlled trial; allo-HSCT, Allogenic hemopoietic stem cell transplant; MRD, Minimal residual disease. 
with MRD data available was relatively small (5). Morita et al. analyzed data from 171 T-ALL patients from the MD Anderson Cancer Center during the period of 2000-2019, which also included a cohort of patients in the study by Jain et al. (17). Of these, 27 patients had ETP-ALL. Similarly, the study found that ETP-ALL was associated with significantly poor EFS and OS compared with other subtypes of T-ALL. Allogeneic HSC transplant at first remission improved the 5-year EFS (36\%vs. $18 \%)$ significantly with a trend of better 5-year OS (36\% vs. $29 \%$ ), although it was not statistically significant. The study revealed the survival benefit of allogenic HSC transplant in ETP-ALL (17).

A retrospective review included 185 adult patients diagnosed with T-ALL from ALL-HR2003 and ALL-HR-11 trials. In that study, 34 patients matched the diagnostic criteria of ETP-ALL. The study showed that the response to induction chemotherapy was significantly poorer than other subtypes of T-ALL. The rate of MRD $>0.1 \%$ at day 35 of treatment was significantly higher. The ETP-ALL was independently associated with poorer EFS and OS compared with other subtypes of T-ALL (67).

A retrospective study included 48 patients with T-ALL/T lymphoblastic lymphoma in a center in Columbia aged 8 months to 81 years. Among these, 7 patients presented an ETP-ALL phenotype. They were treated with various conventional combination chemotherapy protocols for high-risk ALL. The study showed that the risk of relapse of the ETP-ALL subgroup was significantly higher with inferior EFS in the pediatric population (59). The main limitation of the study was the small patient number as well as the heterogeneity of treatment regimens.

The COG-AALL0434 study enrolled a total of 1,596 patients aged 1-31 years old with the diagnosis of T-ALL, including patients with ETP-ALL. Patients received a prednisolone-based, four-drug combination chemotherapy as the induction regimen. Patients were then stratified into low-risk, intermediate-risk, and high-risk subgroups according to the NCI risk classification, prednisolone response, any central nervous system/testis involvement, and bone marrow response after induction therapy. The intermediate-risk and high-risk groups were randomized for nelarabine therapy and the latter achieved a 5year OS of $89.5 \%$ and the 5-year EFS rate was $83.7 \%$. In total, 92 patients with ETP-ALL were taken off the study protocol. Among these patients, 28 received allogenic HSC transplant. From the multivariate analysis of the overall cohort, ETP-ALL status did not have a significant impact on DFS (65). Again, the study showed the benefits of risk-adapted therapy and allogenic HSC transplant in ETP-ALL.

The phase III clinical trials DFCI 05-001 and DFCI 11-001 recruited a total of 123 patients aged 1-21 years with T-ALL, including 21 patients with the ETP-ALL phenotype. They were treated with prednisolone induction and then multiagent chemotherapeutic drugs. All patients with T-ALL were treated with high-risk arms therapy. A significantly higher rate of induction failure was observed in ETP-ALL patients and thus a significantly poorer 5-year EFS. However, the 5-year OS was not significantly different from non-ETP-ALL. The study showed that the adverse prognostic outcome of ETP-ALL could be alleviated by treatment with a high-risk regimen (66).

The UKALL 2003 study recruited patients aged 1-25 years and 388 T-ALL patients were included. Among these, 35 patients had a diagnosis of ETP-ALL. The trial classified patients into standard-, intermediate-, and high-risk based on clinical factors, early morphological response, and cytogenetics. Those standardrisk patients received a three-drug combination and intermediate- and high-risk patients received a four-drug combination for induction. Patients with standard and intermediate risk were stratified into MRD low-risk and MRD high-risk groups, depending on the MRD level. They were then randomized for treatment reduction (for those with undetectable MRD or MRD $<0.01 \%$ post-induction but undetectable after consolidation) or who received treatment intensification (MRD $>0.01 \%$ post-induction) (73). During the median follow-up period of 4 years and 10 months, the 5-year EFS and OS for the ETP-ALL group were not significantly different from other subtypes of T-ALL. The authors attributed the findings to the use of pegylated asparaginase and dexamethasone. Furthermore, the more intensive regimen was given to patients with slow morphological response and the MRD response that occurred more frequently in the ETP-ALL subgroup (60).

A study of 47 adult patients with ETP-ALL was conducted, which included patients from the Group for Research on Adult Acute Lymphoblastic Leukemia (GRAALL)-2003 and -2005 studies. The patients were treated with the GRAALL protocol, a pediatric-inspired protocol. The essence of this protocol is treatment intensification if there is evidence of early treatment resistance, e.g., MRD positivity after induction chemotherapy. In this study, $71.4 \%$ of patients with ETP-ALL had MRD level $\geq 10^{-4}$ at day 42 after treatment and $50 \%$ of patients with MRD level higher than that level after day 84 of treatment were eligible for allogeneic HSC transplant. The 5-year OS was not statistically different from other T-ALL subtypes. Of note, approximately $48.6 \%$ of ETP-ALL patients received allogenic stem cell transplant and the ETP-ALL phenotype was associated with better outcome upon allogenic stem cell transplantation. Patients with ETP-ALL achieved an inferior 5-year OS without allogenic stem cell transplant (62).

Data from patients treated with the NOPHO 2008 protocol, an unmodified pediatric protocol that included patients aged 145 years old and a total of $278 \mathrm{~T}$-ALL patients, were included. Among them, 37 patients belonged to the ETP-ALL subgroup. Patients were stratified into intermediate- and high-risk groups according to MRD response at day 29. Patients would be eligible for allogenic HSC transplant if MRD was $\geq 0.1 \%$ at day 79 or MRD was $>5 \%$ at day 29 . The results showed that ETP-ALL patients did not achieve a statistically significantly different relapse rate or OS compared with the non-ETP-ALL patients, although they had slow MRD response and thus most patients received high-risk arm therapy or allogenic HSC transplant (69). Again, this study showed an improved outcome for ETP-ALL when treated with risk-adapted therapy and allogenic HSC transplant might have a role in improving outcome of ETPALL patients. 
Another study involving 16 patients with ETP-ALL who underwent allogeneic stem cell transplant followed by treatment with hyper-CVAD plus or minus nelarabine achieved a 3 -year OS of $47 \%$ for ETP-ALL patients, which was not statistically different from other T-ALL subtypes (63). However, adult patients with T-ALL carrying IL7R mutations did not show improvement in OS after allogenic HSC transplant, in contrast with those patients without $I L 7 R$ mutations. Patients diagnosed as ETP-ALL had a higher rate of $I L 7 R$ mutations in that study, although some patients with non-ETP-ALL phenotype also carried $I L 7 R$ mutations (47).

In summary, evidence from recent studies indicates that riskadapted therapy with treatment intensification carries survival benefits to both pediatric and adult ETP-ALL patients. Allogenic hemopoietic stem cell transplant may have a role in alleviating adverse outcome of ETP-ALL as is evident from recent studies, especially those involving adult patients. Further studies are needed to evaluate the role of allogeneic stem transplant in managing ETP-ALL, especially in the pediatric population and further research in evaluating the role of different genetic aberrations benefitting from HSC transplant are needed. Some genetic aberrations in ETP-ALL, for example, NOTCH1 and $I L 7 R$, carry prognostic impact, and the approach of disease prognostication by various genetic aberrations requires extensive validation in subsequent studies.

\section{NOVEL THERAPIES}

Given the dismal prognosis of relapse/refractory disease of ETPALL and the challenge in managing patients who cannot tolerate intensive chemotherapy, there is an urgent need to develop novel treatments for ETP-ALL based on the understanding of disease biology and molecular mechanisms. Table 8 summarizes the novel therapies available for ETP-ALL. Table 9 summarizes various ongoing clinical trials involving novel therapies.

\section{Venetoclax}

BCL2 was found to be highly expressed in the DN1 stage of early T-cell progenitors (CD44-positive/CD25-negative/CD4 and $\mathrm{CD} 8$ double-negative). A study utilizing mitochondrial $\mathrm{BH} 3$ profiling found that ETP-ALL is BCL-2-dependent for its antiapoptotic activity. This provided a rationale for treatment of ETP-ALL with the specific BCL-2 inhibitor, venetoclax. The sensitivity of venetoclax towards ETP-ALL was demonstrated in patient-derived xenograft models of ETP-ALL leukemic cells $(74,75)$.

A case report showed promising therapeutic effects of combined bortezomib and venetoclax treatment in patients with relapse/refractory ETP-ALL, with the ability to achieve hematological response and bridge to allogenic HSC transplant (76). Another case report showed successful treatment of relapse ETP-ALL by combining the venetoclax and HAG regime (homoharringtonine, cytarabine, and G-CSF) and the patient remained in remission after allogenic HSC transplant (77).
Combination of venetoclax and conventional chemotherapy was able to achieve remission with MRD negativity and bridge to allogenic HSC transplant in adult patients with ETP-ALL as documented in a case report (78). A further case report demonstrated that combining venetoclax and decitabine could induce morphological remission and MRD negativity in primary refractory ETP-ALL in adult patients with TP53 mutation (79).

A study recruited a total of 13 patients aged $20-75$ years old with relapse/refractory T-ALL, including 5 patients with ETPALL. All patients were treated with venetoclax combined with chemotherapy or decitabine. Morphological remission was achieved in $60 \%$ of patients, while one patient had MRD negativity and that patient had ETP-ALL phenotype (80).

A phase 1 clinical study (NCT03181126) enrolled patients aged older than 4 years with relapse/refractory ALL, including 16 patients with T-ALL and treated patients with the combination venetoclax and navitoclax (a BCL-2/BCL-XL/BCL-W inhibitor). The overall response rate, including complete remission and complete remission with incomplete count recovery, was 38\%. Among those patients with response, 66.7\% achieved MRD negativity (81).

Additional phase I/II clinical trials are being conducted evaluating treatment of relapse/refractory T-ALL in adult patients using venetoclax combined with chemotherapy or other novel agents (NCT03808610, NCT03504644, NCT03808610, and NCT04752163). A safety and pharmacokinetics study of venetoclax is ongoing for relapse/ refractory T-ALL in pediatric and young adults (NCT03236857). Venetoclax appears to be a promising agent against ETP-ALL either as monotherapy or combined with other agents. Data from various clinical studies will be available in the near future to delineate the role of venetoclax in treatment of ETP-ALL.

\section{Ruxolitinib}

IL7R mutations lead to hyperactivation of the IL7 pathway and cause resistance to steroid treatment. Hyperactivation of the JAK/STAT pathway is also observed in response to IL7 pathway stimulation (55). Upregulation of JAK/STAT pathway proteins and activities is also observed in ETP-ALL patients with PRC2 mutations, which is prevalent in patients with ETP-ALL. Moreover, JAK/STAT pathway hyperactivation is a common finding in patient samples of ETP-ALL (82). Therefore, ruxolitinib, an inhibitor for both JAK1 and JAK2, is a promising agent for ETP-ALL treatment $(28,57,58)$. The administration of ruxolitinib was shown to reverse the effects of steroid resistance under the stimulation of the IL7 pathway (55). Ruxolitinib also significantly reduced leukemic burden in a patient-derived xenograft model of ETP-ALL (82). A randomized controlled trial (RCT) is currently recruiting patients with newly diagnosed pediatric ALL, including T-ALL, and they will be treated with conventional combined chemotherapy and ruxolitinib for those patients with JAK/ STAT pathway aberration. The trial will investigate whether there will be improvement of EFS and OS after combination treatment with ruxolitinib (NCT03117751). More clinical studies are required to evaluate the role of ruxolitinib as monotherapy or combination with other agents in the treatment of ETP-ALL. 
TABLE 8 | Summary of potential novel therapies available for ETP-ALL.

\begin{tabular}{|c|c|c|c|c|c|}
\hline $\begin{array}{l}\text { Type of Novel } \\
\text { Therapy }\end{array}$ & Rationale & $\begin{array}{l}\text { Therapeutic } \\
\text { Target }\end{array}$ & $\begin{array}{l}\text { Single Treatment or Proposed } \\
\text { Combined Treatment }\end{array}$ & $\begin{array}{l}\text { Data from Pre- } \\
\text { clinical Studies } \\
\text { for ETP-ALL } \\
\text { Available? }\end{array}$ & $\begin{array}{l}\text { Data from Clinical Studies for } \\
\text { ETP-ALL Patients Available } \\
\text { (Except Case Reports)? }\end{array}$ \\
\hline $\begin{array}{l}\text { JAK inhibitor } \\
\text { (ruxolitinib) }\end{array}$ & $\begin{array}{l}\text { JAK/STAT pathway } \\
\text { hyperactivation is common in ETP- } \\
\text { ALL }\end{array}$ & JAK & Single treatment & Yes & No \\
\hline $\begin{array}{l}\text { Anti-CD33 } \\
\text { (gemtuzumab) }\end{array}$ & $\begin{array}{l}\text { CD33 expression is frequently } \\
\text { present in ETP-ALL }\end{array}$ & CD33 & Single treatment & Yes & No \\
\hline $\begin{array}{l}\text { Anti-CD38 } \\
\text { (daratumumab) }\end{array}$ & $\begin{array}{l}\text { CD38 expression is frequently } \\
\text { present in ETP-ALL }\end{array}$ & CD38 & $\begin{array}{l}\text { 1. Single treatment } \\
\text { 2. Combined with nelarabine }\end{array}$ & Yes & No \\
\hline Anti-CD123 & $\begin{array}{l}\text { CD123 expression is prevalent in } \\
\text { ETP-ALL }\end{array}$ & CD123 & Single treatment & No & No \\
\hline CAR-T & $\begin{array}{l}\text { Genetically engineered patient's T } \\
\text { cells to target against various } \\
\text { antigens present on ETP-ALL }\end{array}$ & CD5, CD7 & Single treatment & Yes & No \\
\hline $\begin{array}{l}\text { Hypomethylating } \\
\text { agents } \\
\text { (decitabine, } \\
\text { azacytidine) }\end{array}$ & $\begin{array}{l}\text { 1. DNA hypermethylation } \\
\text { associated with PRC2 mutations } \\
\text { 2. High rate of DNMT2A mutation } \\
\text { in adult ETP-ALL }\end{array}$ & $\begin{array}{l}\text { 1. Targeting } \\
\text { epigenetic } \\
\text { regulation of gene } \\
\text { transcriptions } \\
\text { 2. Upregulation of } \\
\text { NOXA in AML }\end{array}$ & $\begin{array}{l}\text { Combination therapy with venetoclax } \\
\text { or combined chemotherapy }\end{array}$ & No & No \\
\hline $\begin{array}{l}\text { BCL-2 inhibitor } \\
\text { (venetoclax) }\end{array}$ & $\begin{array}{l}\text { ETP-ALL is highly dependent on } \\
\text { BCL-2 activity }\end{array}$ & BCL-2 & $\begin{array}{l}\text { 1. Single treatment } \\
\text { 2. Combination therapy with } \\
\text { conventional chemotherapy, } \\
\text { hypomethylating agents, bortezomib, } \\
\text { navitoclax }\end{array}$ & Yes & Yes \\
\hline FLT3 inhibitors & $\begin{array}{l}\text { FLT3-ITD and FLT3-TKD } \\
\text { mutations are common in ETP-ALL }\end{array}$ & FLT3 & Single treatment & No & No \\
\hline BET inhibitors & $\begin{array}{l}\text { Frequent PRC2 mutations in ETP- } \\
\text { ALL }\end{array}$ & BET protein & Single treatment & Yes & No \\
\hline
\end{tabular}

\section{Anti-CD33}

CD33 is commonly expressed in AML, and the addition of the monoclonal antibody against CD33, gemtuzumab, into standard chemotherapy could improve survival in patients with AML without poor-risk cytogenetics (83). An earlier report showed that gemtuzumab was active against CD33-positive B lymphoblastic leukemia, in both in vitro and in vivo models (84). ETP-ALL commonly present CD33 expression, which accounted for $67 \%$ of ETP-ALL in one study. Targeted therapy of anti-CD33 demonstrated cytotoxicity in an ETP-ALL cell line (14). However, larger-scale clinical trials to study the role of gemtuzumab in ETP-ALL are lacking.

\section{Anti-CD38}

A study including 196 patients with T-ALL aged from 1 to 53 years, which consisted of 188 diagnostic samples and 35 relapsed samples, showed that CD38 was positive (using $\geq 20 \%$ positivity as the cutoff) in $97.9 \%$ and $82.9 \%$ of diagnostic and relapsed samples, respectively. The percentage of blasts positive for CD38 were similar in the ETP-ALL versus non-ETP-ALL subgroup. The results also showed that CD38 expression was stable even in relapsed samples (85). Another study including 10 patients with ETP-ALL showed that CD38 expression was stable over multiple courses of chemotherapy. Thus, targeting CD38 expression is an attractive approach for treatment of ETP-ALL. Treatment of CD38-expressing T-ALL with daratumumab was successful in the xenograft model, including seven patient-derived xenografts of ETP-ALL (86). Furthermore, case reports showed that daratumumab was effective in achieving morphological remission and MRD negativity after MRD relapse postallogenic HSC transplant and extramedullary relapse in adult patients with blasts expressing CD38 (87-89). Another case report demonstrated that sequential administration of nelarabine and daratumumab was able to induce morphological remission and MRD negativity in patients after refractory to conventional chemotherapeutic induction regimens (90).

A phase 2 clinical trial recruiting 32 patients with relapsed/ refractory CD38-positive T-ALL or B-ALL is ongoing. The trial plans to include patients aged 1-30 years and to be treated with daratumumab combined with chemotherapy (NCT03384654). Another phase 2 trial plans to include 96 patients aged 28 days to 18 years with relapsed AML or ALL (both B-ALL and T-ALL) and is currently ongoing, and patients will be treated with isatuximab, another monoclonal antibody against CD38 combined with chemotherapy (NCT03860844).

\section{Anti-CD123}

CD123 is expressed in several hematological malignancies, including hairy cell leukemia (91), blastic plasmacytoid dendritic cell neoplasm (92), and AML (93). A study involving 30 patients with T-ALL found that CD123 was expressed in $43.3 \%$ of T-ALL cases, which was less frequent than in B-ALL. However, CD123 expression was more prevalent in ETP-ALL 
TABLE 9 | Ongoing clinical trials on novel therapies.

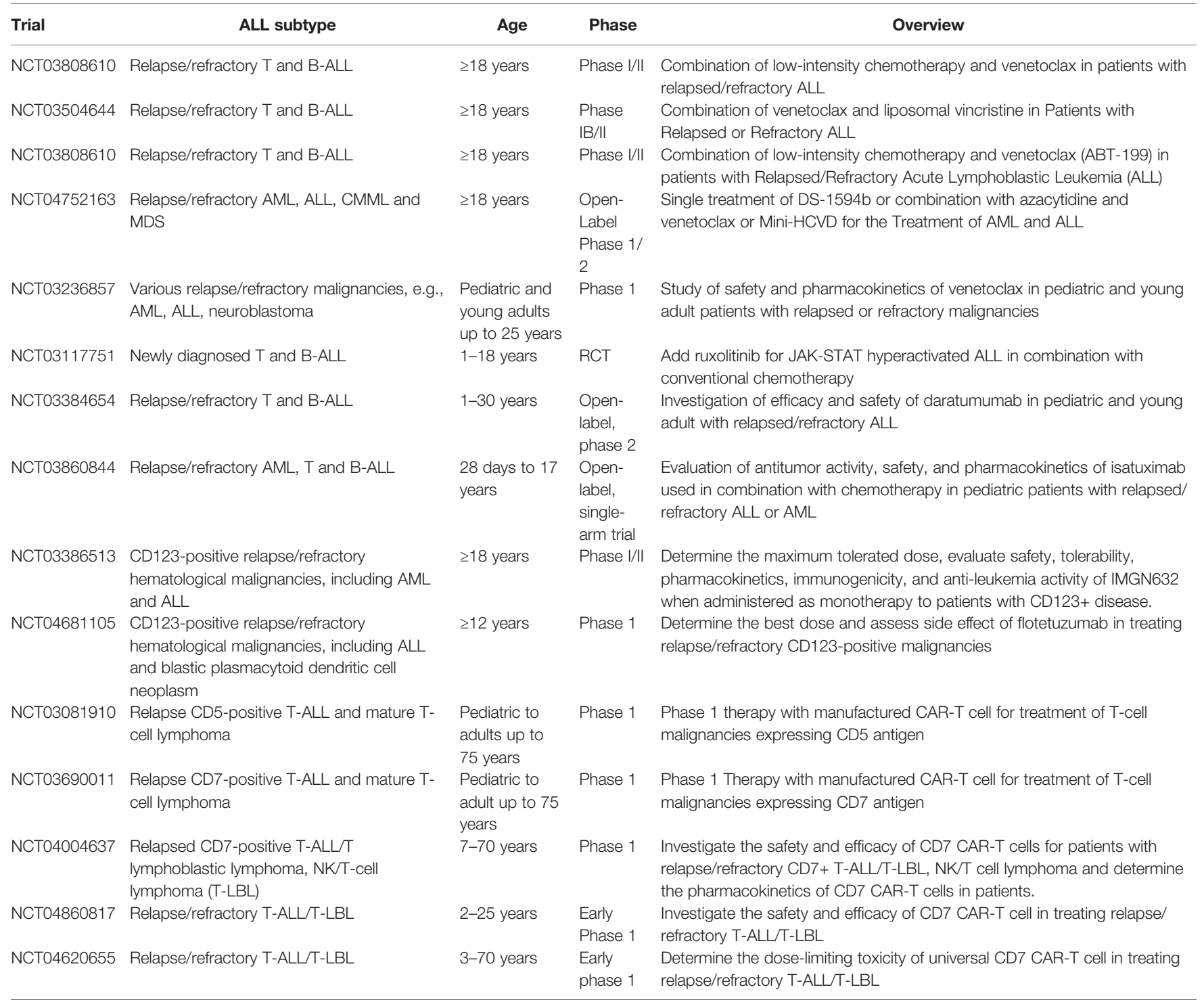

and early non-ETP-ALL phenotype, which constitute approximately $92.3 \%$ of T-ALL overall. Thus, CD123 is another novel target for therapy. A monoclonal antibody against CD123 was proven to be effective against B-ALL in a pre-clinical study (94). A phase I clinical trial will recruit 40 patients aged 12 years or above with CD123-positive hematological malignancies, including T-ALL to be treated with a single agent, flotetuzumab, a monoclonal antibody against CD123 (NCT04681105). Another phase I/II study (NCT03386513) will recruit 252 patients aged 18 years or above with the diagnosis of CD123-positive hematological malignancies including T-ALL to be treated with a single agent of monoclonal antibody against CD123 (IMGGN632).

\section{CAR-T therapy}

Chimeric antigen receptor engineered T-cell (CAR-T) therapy is a promising therapy for treating B lymphoblastic leukemia (95, 96). However, since normal $\mathrm{T}$ cells and malignant $\mathrm{T}$ cells share a similar antigen profile, the utility of CAR-T therapy in treating T-cell hematological malignancies is limited. A study group using CRISPR/Cas9 technology has deleted CD7 and the T-cell receptor and engineered to target $\mathrm{CD} 7$ in malignant cells. A preclinical model showed excellent activity against T-ALL cell line xenograft model and a patient-derived xenograft model. A fratricide assay showed that minimal fratricide was detected $(97,98)$. These findings were very promising for CAR-T therapy in T-cell malignancies. Another pre-clinical study using CAR-T cells targets CD7 expression in leukemia cells by downregulating CD7 expression in CAR-T cells. The approach showed effective killing of primary ETP-ALL leukemic cells in patient-derived xenografts without significant fratricide (99). CAR-T cells targeting CD5 were also effective in killing primary T-ALL in a pre-clinical model (100).

Various phase I clinical trials investigating CD7-targeting CAR-T cells are recruiting patients with T-cell hematological malignancies including T-ALL and are ongoing (NCT03690011, 
NCT04004637, NCT04860817, and NCT04620655). A clinical trial of CD5 targeting CAR-T cells for T-cell malignancies, including T-ALL, is also ongoing (NCT03081910).

\section{Other Potential Novel Therapies}

Drugs targeting epigenetic pathways, such as with hypomethylating agents azacytidine and decitabine, could be useful, because of the association of DNA hypermethylation with PRC2 mutation (58). As suggested previously, despite the lower rate of $P R C 2$ mutations in adults, there is a higher rate of DNMT3A mutation that also supports the use of hypomethylating agents in adult patients (101). However, the use of hypomethylating agents in treating ETP-ALL had not been fully investigated in a pre-clinical model and no clinical studies are available that address this issue. Since ETP-ALL commonly presents mutations of genes involved in epigenetic regulation and BCL2 overexpression, the combination of azacytidine or decitabine with venetoclax is a reasonable option as a novel combination strategy. Moreover, a study showed that azacytidine induced expression of the proapoptotic protein NOXA, which enhanced the susceptibility of leukemic cells to venetoclaxinduced apoptosis (102). This combination therapy is a promising approach for treating AML (103). A case report described how combined decitabine and venetoclax was successful in treating a patient with refractory $\mathrm{T}$ lymphoblastic lymphoma, although the patient was diagnosed with the cortical $\mathrm{T}$ subtype of $\mathrm{T}$ lymphoblastic lymphoma (104). Another case series included six patients with relapse/refractory ETP-ALL treated with decitabine combined with G-CSF, low dose cytarabine, and aclarubicin. The treatment successfully brought the disease into control and allowed to bridge into allogenic HSC transplantation (105). Further preclinical and clinical studies to evaluate the combination of hypomethylating agents and venetoclax are needed.

Since both FLT3-TKD and FLT3-ITD mutations are common in ETP-ALL and the prevalence of FLT3 mutations can be up to 35\%, the use of an FLT3 inhibitor also provides a novel treatment approach. However, there are limited pre-clinical studies to evaluate this hypothesis and there are no clinical studies to investigate the use of FLT3 inhibitors in ETP-ALL (106). Sorafenib is a tyrosine kinase inhibitor employed to treat patients with FLT3-mutated AML with promising results (107). A study using an FLT3-transfected cell model to create an FLT3-mutated or FLT3 wild-type phenotype in T-ALL cell lines showed sensitivity towards sorafenib in FLT3-mutated cell lines, although the cell lines used in that study did not exhibit the ETP-ALL phenotype (108).

Another promising novel therapy involves BET inhibitors. In a mouse model of loss-of-function mutations of PRC2 resulting in RAS pathway hyperactivation, tumor growth of peripheral nerve sheath tumors was observed when coupled with another mutation, for example, of NF1. The tumor was sensitive to a BET protein inhibitor in that study (109). Recent pre-clinical studies on mouse models of ETP-ALL showed the efficacy of BET inhibitors for treating ETP-ALL associated with PRC2 mutation (48). Again, this approach has not been evaluated in clinical settings.

Given the growing knowledge of underlying genetics and molecular mechanisms of ETP-ALL, various potential novel therapies are available and some have demonstrated efficacy in treating ETP-ALL in pre-clinical models. Data from clinical studies are emerging. More comprehensive pre-clinical studies and large-scale clinical studies of novel therapies, either used as monotherapy or combined with other agents, are needed to establish their role in treating ETP-ALL.

\section{CONCLUSION}

ETP-ALL is a distinct subtype of T-ALL with a unique immunophenotype and genetic profile. The clinical course is aggressive and management of patients with ETP-ALL is challenging. The outcome of patients is poorer than that of other subtypes of T-ALL in previous studies. The diagnosis of ETP-ALL is also challenging. Despite the limitations of flow immunophenotyping for diagnosis, our proposed definition, which is based on the WHO classification and knowledge of Tcell maturation, will help daily clinical practice for diagnosis. In the future, data from genetic profiling will give us greater insight into acute leukemia classification. Further research is needed to incorporate the data from genetic profiling for subclassification of different types of acute leukemia, including ETP-ALL, into clinical practice. A new classification system based on immunophenotype and genetic profiling may be helpful for disease prognostication and treatment planning (12).

The cellular origin of ETP-ALL is hypothesized to derive from early thymic progenitors. This hypothesis was also verified by pre-clinical studies. With the greater understanding of molecular pathogenesis of various genetic aberrations of ETP-ALL, the exact mechanisms of leukemogenesis will become clearer. However, further studies are needed, especially to dissect the molecular pathogenesis of DNA hypermethylation in leukemogenesis of ETP-ALL.

The clinical management of ETP-ALL is challenging, and the outcome of patients was poor in early patient cohorts. The practice of risk-adapted treatment and allogenic HSC transplantation improved outcomes of those patients in recent clinical studies. However, larger-scale clinical studies are required to establish the role of allogenic hemopoietic stem cell transplant in improving the outcome of patients with ETP-ALL.

Novel therapies are desperately needed by patients with relapse/refractory disease or those who cannot tolerate standard chemotherapeutic treatment. Based on the understanding of molecular pathogenesis, venetoclax and ruxolitinib have been revealed as effective treatments for ETPALL in pre-clinical models and some patients have been successfully treated by venetoclax or its combination with other agents. However, larger-scale clinical studies are needed to better evaluate these agents for treatment of ETP-ALL.

Immunotherapy including monoclonal antibodies and CAR-T therapy is emerging as a successful approach for treating relapse/ refractory B-ALL. These therapies demonstrated efficacy in a preclinical model of ETP-ALL. With the advance of CRISPR/Cas9 technology, CD5- and CD7-targeted CAR-T cells were developed, and they are being introduced into clinical trials, together with monoclonal antibodies against CD33, CD38, and CD123.

Epigenetic aberrations and FLT3 mutations are common in ETP-ALL, which rationalizes the use of hypomethylating agents, 
BET inhibitors, and FLT3 inhibitors as reasonable novel therapies for ETP-ALL. However, these approaches have not been extensively studied, even in pre-clinical models. There is an urgent need for evaluating these agents in treating ETP-ALL, given the current understanding of molecular pathogenesis.

\section{REFERENCES}

1. Guru Murthy GS, Pondaiah SK, Abedin S, Atallah E. Incidence and Survival of T-Cell Acute Lymphoblastic Leukemia in the United States. Leuk Lymphoma (2019) 60:1171-8. doi: 10.1080/10428194.2018.1522442

2. Pui $\mathrm{CH}$, Evans WE. Treatment of Acute Lymphoblastic Leukemia. $N$ Engl J Med (2006) 354:166-78. doi: 10.1056/NEJMra052603

3. Rafei H, Kantarjian HM, Jabbour EJ. Recent Advances in the Treatment of Acute Lymphoblastic Leukemia. Leuk Lymphoma (2019) 60:2606-21. doi: 10.1080/10428194.2019.1605071

4. Arber DA, Orazi A, Hasserjian R, Thiele J, Borowitz MJ, Le Beau MM, et al. The 2016 Revision to the World Health Organization Classification of Myeloid Neoplasms and Acute Leukemia. Blood (2016) 127:2391-405. doi: 10.1182/blood-2016-03-643544

5. Jain N, Lamb AV, O'Brien S, Ravandi F, Konopleva M, Jabbour E, et al. Early T-Cell Precursor Acute Lymphoblastic Leukemia/Lymphoma (ETP-ALL/ LBL) in Adolescents and Adults: A High-Risk Subtype. Blood (2016) 127:1863-9. doi: 10.1182/blood-2015-08-661702

6. Coustan-Smith E, Mullighan CG, Onciu M, Behm FG, Raimondi SC, Pei D, et al. Early T-Cell Precursor Leukaemia: A Subtype of Very High-Risk Acute Lymphoblastic Leukaemia. Lancet Oncol (2009) 10:147-56. doi: 10.1016/ S1470-2045(08)70314-0

7. Raetz EA, Teachey DT. T-Cell Acute Lymphoblastic Leukemia. Hematol Am Soc Hematol Educ Program (2016) 2016:580-8. doi: 10.1182/asheducation2016.1.580

8. Bayon-Calderon F, Toribio ML, Gonzalez-Garcia S. Facts and Challenges in Immunotherapy for T-Cell Acute Lymphoblastic Leukemia. Int J Mol Sci (2020) 21:1-35. doi: 10.3390/ijms21207685

9. Bene MC, Bernier M, Casasnovas RO, Castoldi G, Knapp W, Lanza F, et al. The Reliability and Specificity of C-Kit for the Diagnosis of Acute Myeloid Leukemias and Undifferentiated Leukemias. Blood (1998) 92:596-9. doi: 10.1182/blood.V92.2.596

10. You MJ, Medeiros LJ, Hsi ED. T-Lymphoblastic Leukemia/Lymphoma. Am J Clin Pathol (2015) 144:411-22. doi: 10.1309/AJCPMF03LVSBLHPJ

11. Han X, Bueso-Ramos CE. Precursor T-Cell Acute Lymphoblastic Leukemia/ Lymphoblastic Lymphoma and Acute Biphenotypic Leukemias. Am J Clin Pathol (2007) 127:528-44. doi: 10.1309/2QE3A6EKQ8UYDYRC

12. Inukai T, Kiyokawa N, Campana D, Coustan-Smith E, Kikuchi A, Kobayashi M, et al. Clinical Significance of Early T-Cell Precursor Acute Lymphoblastic Leukaemia: Results of the Tokyo Children's Cancer Study Group Study L9915. Br J Haematol (2012) 156:358-65. doi: 10.1111/j.1365-2141.2011.08955.x

13. Zuurbier L, Gutierrez A, Mullighan CG, Cante-Barrett K, Gevaert AO, de Rooi J, et al. Immature MEF2C-Dysregulated T-Cell Leukemia Patients Have an Early T-Cell Precursor Acute Lymphoblastic Leukemia Gene Signature and Typically Have Non-Rearranged T-Cell Receptors. Haematologica (2014) 99:94-102. doi: 10.3324/haematol.2013.090233

14. Khogeer H, Rahman H, Jain N, Angelova EA, Yang H, Quesada A, et al. Early T Precursor Acute Lymphoblastic Leukaemia/Lymphoma Shows Differential Immunophenotypic Characteristics Including Frequent CD33 Expression and. Vitro Response to Targeted CD33 Ther Br J Haematol (2019) 186:538-48. doi: 10.1111/bjh.15960

15. Chopra A, Bakhshi S, Pramanik SK, Pandey RM, Singh S, Gajendra S, et al. Immunophenotypic Analysis of T-Acute Lymphoblastic Leukemia. A CD5Based ETP-ALL Perspective of non-ETP T-ALL. Eur J Haematol (2014) 92:211-8. doi: 10.1111/ejh.12238

16. Van Vlierberghe P, Ambesi-Impiombato A, Perez-Garcia A, Haydu JE, Rigo I, Hadler M, et al. ETV6 Mutations in Early Immature Human T Cell Leukemias. J Exp Med (2011) 208:2571-9. doi: 10.1084/jem.20112239

\section{AUTHOR CONTRIBUTIONS}

C-FS wrote the article and conceptualized the article. P-hM wrote the article. Both authors reviewed the article. All authors contributed to the article and approved the submitted version.

17. Morita K, Jain N, Kantarjian H, Takahashi K, Fang H, Konopleva M, et al. Outcome of T-Cell Acute Lymphoblastic Leukemia/Lymphoma: Focus on Near-ETP Phenotype and Differential Impact of Nelarabine. Am J Hematol (2021) 96:589-98. doi: 10.1002/ajh.26144

18. Tavakoli Shirazi P, Eadie LN, Heatley SL, Hughes TP, Yeung DT, White DL. The Effect of Co-Occurring Lesions on Leukaemogenesis and Drug Response in T-ALL and ETP-ALL. Br J Cancer (2020) 122:455-64. doi: 10.1038/s41416-019-0647-7

19. Noronha EP, Marques LVC, Andrade FG, Sardou-Cezar I, Dos SantosBueno FV, Zampier CDP, et al. T-Lymphoid/Myeloid Mixed Phenotype Acute Leukemia and Early T-Cell Precursor Lymphoblastic Leukemia Similarities With NOTCH1 Mutation as a Good Prognostic Factor. Cancer Manag Res (2019) 11:3933-43. doi: 10.2147/CMAR.S196574

20. Bond J, Krzywon A, Lhermitte L, Roumier C, Roggy A, Belhocine M, et al. A Transcriptomic Continuum of Differentiation Arrest Identifies Myeloid Interface Acute Leukemias With Poor Prognosis. Leukemia (2021) 35:724-36. doi: 10.1038/s41375-020-0965-Z

21. Anand P, Guillaumet-Adkins A, Dimitrova V, Yun H, Drier Y, Sotudeh N, et al. Single Cell RNA-Seq Reveals Developmental Plasticity With Coexisting Oncogenic and Immune Evasion Programs in ETP-ALL. Blood (2021) 137 (18): 2463-80. doi: 10.1182/blood.2019004547

22. Dworzak MN, Buldini B, Gaipa G, Ratei R, Hrusak O, Luria D, et al. AIEOPBFM Consensus Guidelines 2016 for Flow Cytometric Immunophenotyping of Pediatric Acute Lymphoblastic Leukemia. Cytometry B Clin Cytom (2018) 94:82-93. doi: 10.1002/cyto.b.21518

23. Porwit A, Bene MC. Multiparameter Flow Cytometry Applications in the Diagnosis of Mixed Phenotype Acute Leukemia. Cytometry B Clin Cytom (2019) 96:183-94. doi: 10.1002/cyto.b.21783

24. Porwit A, Bene MC. Acute Leukemias of Ambiguous Origin. Am J Clin Pathol (2015) 144:361-76. doi: 10.1309/AJCPSTU55DRQEGTE

25. Bell JJ, Bhandoola A. The Earliest Thymic Progenitors for T Cells Possess Myeloid Lineage Potential. Nature (2008) 452:764-7. doi: 10.1038/ nature 06840

26. Wada H, Masuda K, Satoh R, Kakugawa K, Ikawa T, Katsura Y, et al. Adult T-Cell Progenitors Retain Myeloid Potential. Nature (2008) 452:768-72. doi: 10.1038/nature06839

27. Ugale A, Sawen P, Dudenhoffer-Pfeifer M, Wahlestedt M, Norddahl GL, Bryder D. MLL-ENL-Mediated Leukemia Initiation at the Interface of Lymphoid Commitment. Oncogene (2017) 36:3207-12. doi: 10.1038/ onc. 2016.470

28. Booth CAG, Barkas N, Neo WH, Boukarabila H, Soilleux EJ, Giotopoulos G, et al. Ezh2 and Runx1 Mutations Collaborate to Initiate Lympho-Myeloid Leukemia in Early Thymic Progenitors. Cancer Cell (2018) 33:274-291 e278. doi: 10.1016/j.ccell.2018.01.006

29. Zhang J, Ding L, Holmfeldt L, Wu G, Heatley SL, Payne-Turner D, et al. The Genetic Basis of Early T-Cell Precursor Acute Lymphoblastic Leukaemia. Nature (2012) 481:157-63. doi: 10.1038/nature10725

30. Girardi T, Vicente C, Cools J, De Keersmaecker K. The Genetics and Molecular Biology of T-ALL. Blood (2017) 129:1113-23. doi: 10.1182/ blood-2016-10-706465

31. Belver L, Ferrando A. The Genetics and Mechanisms of $\mathrm{T}$ Cell Acute Lymphoblastic Leukaemia. Nat Rev Cancer (2016) 16:494-507. doi: 10.1038/nrc.2016.63

32. Liu Y, Easton J, Shao Y, Maciaszek J, Wang Z, Wilkinson MR, et al. The Genomic Landscape of Pediatric and Young Adult T-Lineage Acute Lymphoblastic Leukemia. Nat Genet (2017) 49:1211-8. doi: 10.1038/ng.3909

33. Noronha EP, Marques LVC, Andrade FG, Thuler LCS, Terra-Granado E, Pombo-de-Oliveira MS, et al. The Profile of Immunophenotype and 
Genotype Aberrations in Subsets of Pediatric T-Cell Acute Lymphoblastic Leukemia. Front Oncol (2019) 9:316. doi: 10.3389/fonc.2019.00316

34. Homminga I, Pieters R, Langerak AW, de Rooi JJ, Stubbs A, Verstegen M, et al. Integrated Transcript and Genome Analyses Reveal NKX2-1 and MEF2C as Potential Oncogenes in T Cell Acute Lymphoblastic Leukemia. Cancer Cell (2011) 19:484-97. doi: 10.1016/j.ccr.2011.02.008

35. McCormack MP, Young LF, Vasudevan S, de Graaf CA, Codrington R, Rabbitts TH, et al. The Lmo2 Oncogene Initiates Leukemia in Mice by Inducing Thymocyte Self-Renewal. Science (2010) 327:879-83. doi: 10.1126/ science. 1182378

36. McCormack MP, et al. Requirement for Lyl1 in a Model of Lmo2-Driven Early T-Cell Precursor ALL. Blood (2013) 122:2093-103. doi: 10.1182/blood2012-09-458570

37. Li L, Leid M, Rothenberg EV. An Early T Cell Lineage Commitment Checkpoint Dependent on the Transcription Factor Bcl11b. Science (2010) 329:89-93. doi: 10.1126/science.1188989

38. Ha VL, Luong A, Li F, Casero D, Malvar J, Kim YM, et al. The T-ALL Related Gene BCL11B Regulates the Initial Stages of Human T-Cell Differentiation. Leukemia (2017) 31:2503-14. doi: 10.1038/leu.2017.70

39. Van Vlierberghe P, Ambesi-Impiombato A, De Keersmaecker K, Hadler M, Paietta E, Tallman MS, et al. Prognostic Relevance of Integrated Genetic Profiling in Adult T-Cell Acute Lymphoblastic Leukemia. Blood (2013) 122:74-82. doi: 10.1182/blood-2013-03-491092

40. Egawa T, Tillman RE, Naoe Y, Taniuchi I, Littman DR. The Role of the Runx Transcription Factors in Thymocyte Differentiation and in Homeostasis of Naive T Cells. J Exp Med (2007) 204:1945-57. doi: 10.1084/jem.20070133

41. Hosoya T, Kuroha T, Moriguchi T, Cummings D, Maillard I, Lim KC, et al. GATA-3 Is Required for Early T Lineage Progenitor Development. J Exp Med (2009) 206:2987-3000. doi: 10.1084/jem.20090934

42. Fransecky L, Neumann M, Heesch S, Schlee C, Ortiz-Tanchez J, Heller S, et al. Silencing of GATA3 Defines a Novel Stem Cell-Like Subgroup of ETPALL. J Hematol Oncol (2016) 9:95. doi: 10.1186/s13045-016-0324-8

43. Homminga I, Pieters R, Langerak A, de Rooi J, Stubbs A, Verstegen M, et al. MEF2C as Novel Oncogene for Early T-Cell Precursor (ETP) Leukemia. Blood (2010) 116:9-9. doi: 10.1182/blood.V116.21.9.9

44. Ferrando AA, Armstrong SA, Neuberg DS, Sallan SE, Silverman LB, Korsmeyer SJ, et al. Gene Expression Signatures in MLL-Rearranged TLineage and B-Precursor Acute Leukemias: Dominance of HOX Dysregulation. Blood (2003) 102:262-8. doi: 10.1182/blood-2002-10-3221

45. Bach C, Buhl S, Mueller D, Garcia-Cuellar MP, Maethner E, Slany RK. Leukemogenic Transformation by HOXA Cluster Genes. Blood (2010) 115:2910-8. doi: 10.1182/blood-2009-04-216606

46. Bond J, Marchand T, Touzart A, Cieslak A, Trinquand A, Sutton L, et al. An Early Thymic Precursor Phenotype Predicts Outcome Exclusively in HOXAOverexpressing Adult T-Cell Acute Lymphoblastic Leukemia: A Group for Research in Adult Acute Lymphoblastic Leukemia Study. Haematologica (2016) 101:732-40. doi: 10.3324/haematol.2015.141218

47. Kim R, Boissel N, Touzart A, Leguay T, Thonier F, Thomas X, et al. Adult TCell Acute Lymphoblastic Leukemias With IL7R Pathway Mutations Are Slow-Responders Who Do Not Benefit From Allogeneic Stem-Cell Transplantation. Leukemia (2020) 34:1730-40. doi: 10.1038/s41375-0190685-4

48. Andrieu GP, Kohn M, Simonin M, Smith C, Cieslak A, Dourthe ME, et al. PRC2 Loss of Function Confers a Targetable Vulnerability to BET Proteins in T-ALL. Blood (2021) 138(19):1855-69. doi: 10.1182/blood.2020010081

49. Ziegler SF, Liu YJ. Thymic Stromal Lymphopoietin in Normal and Pathogenic T Cell Development and Function. Nat Immunol (2006) 7:709-14. doi: 10.1038/ni1360

50. Treanor LM, Zhou S, Janke L, Churchman ML, Ma Z, Lu T, et al. Interleukin-7 Receptor Mutants Initiate Early T Cell Precursor Leukemia in Murine Thymocyte Progenitors With Multipotent Potential. J Exp Med (2014) 211:701-13. doi: 10.1084/jem.20122727

51. Lodewijckx I, Cools J. Deregulation of the Interleukin-7 Signaling Pathway in Lymphoid Malignancies. Pharmaceuticals (Basel) (2021) 14:1-18. doi: 10.3390/ph14050443

52. Karawajew L, Ruppert V, Wuchter C, Kösser A, Schrappe M, Dörken B, et al. Inhibition of In Vitro Spontaneous Apoptosis by IL-7 Correlates With Bcl-2 Up-Regulation, Cortical/Mature Immunophenotype, and Better Early
Cytoreduction of Childhood T-Cell Acute Lymphoblastic Leukemia. Blood (2000) 96:297-306. doi: 10.1182/blood.V96.1.297

53. Oliveira ML, Akkapeddi P, Ribeiro D, Melao A, Barata JT. IL-7R-Mediated Signaling in T-Cell Acute Lymphoblastic Leukemia: An Update. Adv Biol Regul (2019) 71:88-96. doi: 10.1016/j.jbior.2018.09.012

54. Barata JT, Cardoso AA, Nadler LM, Boussiotis VA. Interleukin-7 Promotes Survival and Cell Cycle Progression of T-Cell Acute Lymphoblastic Leukemia Cells by Down-Regulating the Cyclin-Dependent Kinase Inhibitor P27(Kip1). Blood (2001) 98:1524-31. doi: 10.1182/ blood.v98.5.1524

55. IDelgado-Martin C, Meyer LK, Huang BJ, Shimano KA, Zinter MS, Nguyen JV, et al. JAK/STAT Pathway Inhibition Overcomes IL7-Induced Glucocorticoid Resistance in a Subset of Human T-Cell Acute Lymphoblastic Leukemias. Leukemia (2017) 31:2568-76. doi: 10.1038/leu.2017.136

56. Margueron R, Reinberg D. The Polycomb Complex PRC2 and its Mark in Life. Nature (2011) 469:343-9. doi: 10.1038/nature09784

57. Danis E, Yamauchi T, Echanique K, Zhang X, Haladyna JN, Riedel SS, et al. Ezh2 Controls an Early Hematopoietic Program and Growth and Survival Signaling in Early T Cell Precursor Acute Lymphoblastic Leukemia. Cell Rep (2016) 14:1953-65. doi: 10.1016/j.celrep.2016.01.064

58. Wang C, Oshima M, Sato D, Matsui H, Kubota S, Aoyama K, et al. Ezh2 Loss Propagates Hypermethylation at T Cell Differentiation-Regulating Genes to Promote Leukemic Transformation. J Clin Invest (2018) 128:3872-86. doi: 10.1172/JCI94645

59. Allen A, Sireci A, Colovai A, Pinkney K, Sulis M, Bhagat G, et al. Early T-Cell Precursor Leukemia/Lymphoma in Adults and Children. Leuk Res (2013) 37:1027-34. doi: 10.1016/j.leukres.2013.06.010

60. Patrick K, Wade R, Goulden N, Mitchell C, Moorman AV, Rowntree C, et al. Outcome for Children and Young People With Early T-Cell Precursor Acute Lymphoblastic Leukaemia Treated on a Contemporary Protocol, UKALL 2003. Br J Haematol (2014) 166:421-4. doi: 10.1111/bjh.12882

61. Sayed DM, Sayed HAR, Raslan HN, Ali AM, Zahran A, Al-Hayek R, et al. Outcome and Clinical Significance of Immunophenotypic Markers Expressed in Different Treatment Protocols of Pediatric Patients With TALL in Developing Countries. Clin Lymphoma Myeloma Leuk (2017) 17:443-9. doi: 10.1016/j.clml.2017.05.012

62. Bond J, Graux C, Lhermitte L, Lara D, Cluzeau T, Leguay T, et al. Early Response-Based Therapy Stratification Improves Survival in Adult Early Thymic Precursor Acute Lymphoblastic Leukemia: A Group for Research on Adult Acute Lymphoblastic Leukemia Study. J Clin Oncol (2017) 35:268391. doi: 10.1200/JCO.2016.71.8585

63. Brammer JE, Saliba RM, Jorgensen JL, Ledesma C, Gaballa S, Poon M, et al. Multi-Center Analysis of the Effect of T-Cell Acute Lymphoblastic Leukemia Subtype and Minimal Residual Disease on Allogeneic Stem Cell Transplantation Outcomes. Bone Marrow Transplant (2017) 52:20-7. doi: $10.1038 / \mathrm{bmt} .2016 .194$

64. Fuhrmann S, Schabath R, Moricke A, Zimmermann M, Kunz JB, Kulozik AE, et al. Expression of CD56 Defines a Distinct Subgroup in Childhood TALL With Inferior Outcome. Results of the ALL-BFM 2000 Trial. Br J Haematol (2018) 183:96-103. doi: 10.1111/bjh.15503

65. Dunsmore KP, Winter SS, Devidas M, Wood BL, Esiashvili N, Chen Z, et al. Children's Oncology Group AALL0434: A Phase III Randomized Clinical Trial Testing Nelarabine in Newly Diagnosed T-Cell Acute Lymphoblastic Leukemia. J Clin Oncol (2020) 38:3282-93. doi: 10.1200/JCO.20.00256

66. Burns MA, Place AE, Stevenson KE, Gutierrez A, Forrest S, Pikman Y, et al. Identification of Prognostic Factors in Childhood T-Cell Acute Lymphoblastic Leukemia: Results From DFCI ALL Consortium Protocols 05-001 and 11-001. Pediatr Blood Cancer (2021) 68:e28719. doi: 10.1002/ pbc. 28719

67. Genesca E, Morgades M, Montesinos P, Barba P, Gil C, Guardia R, et al. Unique Clinico-Biological, Genetic and Prognostic Features of Adult Early T-Cell Precursor Acute Lymphoblastic Leukemia. Haematologica (2020) 105:e294-7. doi: 10.3324/haematol.2019.225078

68. Conter V, Valsecchi MG, Buldini B, Parasole R, Locatelli F, Colombini A, et al. Early T-Cell Precursor Acute Lymphoblastic Leukaemia in Children Treated in AIEOP Centres With AIEOP-BFM Protocols: A Retrospective Analysis. Lancet Haematol (2016) 3:e80-6. doi: 10.1016/s2352-3026(15) 00254-9 
69. Quist-Paulsen P, Toft N, Heyman M, Abrahamsson J, Griskevicius L, Hallbook H, et al. T-Cell Acute Lymphoblastic Leukemia in Patients 1-45 Years Treated With the Pediatric NOPHO ALL2008 Protocol. Leukemia (2020) 34:347-57. doi: 10.1038/s41375-019-0598-2

70. Gutierrez A, Dahlberg SE, Neuberg DS, Zhang J, Grebliunaite R, Sanda T, et al. Absence of Biallelic TCRgamma Deletion Predicts Early Treatment Failure in Pediatric T-Cell Acute Lymphoblastic Leukemia. J Clin Oncol (2010) 28:3816-23. doi: 10.1200/JCO.2010.28.3390

71. Manabe A, Ohara A, Hasegawa D, Koh K, Saito T, Kiyokawa N, et al. Significance of the Complete Clearance of Peripheral Blasts After 7 Days of Prednisolone Treatment in Children With Acute Lymphoblastic Leukemia: The Tokyo Children's Cancer Study Group Study L99-15. Haematologica (2008) 93:1155-60. doi: 10.3324/haematol.12365

72. Schrappe M, Valsecchi MG, Bartram CR, Schrauder A, Panzer-Grumayer R, Moricke A, et al. Late MRD Response Determines Relapse Risk Overall and in Subsets of Childhood T-Cell ALL: Results of the AIEOP-BFM-ALL 2000 Study. Blood (2011) 118:2077-84. doi: 10.1182/blood-2011-03-338707

73. Vora A, Goulden N, Wade R, Mitchell C, Hancock J, Hough R, et al. Treatment Reduction for Children and Young Adults With Low-Risk Acute Lymphoblastic Leukaemia Defined by Minimal Residual Disease (UKALL 2003): A Randomised Controlled Trial. Lancet Oncol (2013) 14:199-209. doi: 10.1016/s1470-2045(12)70600-9

74. Chonghaile TN, Roderick JE, Glenfield C, Ryan J, Sallan SE, Silverman LB, et al. Maturation Stage of T-Cell Acute Lymphoblastic Leukemia Determines BCL-2 Versus BCL-XL Dependence and Sensitivity to ABT-199. Cancer Discov (2014) 4:1074-87. doi: 10.1158/2159-8290.CD-14-0353

75. Khaw SL, Suryani S, Evans K, Richmond J, Robbins A, Kurmasheva RT, et al. Venetoclax Responses of Pediatric ALL Xenografts Reveal Sensitivity of MLL-Rearranged Leukemia. Blood (2016) 128:1382-95. doi: 10.1182/blood2016-03-707414

76. La Starza R, Cambo B, Pierini A, Bornhauser B, Montanaro A, Bourquin JP, et al. Venetoclax and Bortezomib in Relapsed/Refractory Early T-Cell Precursor Acute Lymphoblastic Leukemia. JCO Precis Oncol (2019) 3:1-6. doi: 10.1200/PO.19.00172

77. Zhang X, Li J, Jin J, Yu W. Relapsed/refractory Early T-Cell Precursor Acute Lymphoblastic Leukemia was Salvaged by Venetoclax Plus HAG Regimen. Ann Hematol (2020) 99:395-7. doi: 10.1007/s00277-019-03902-9

78. Arora S, Vachhani P, Bachiashvili K, Jamy O. Venetoclax With Chemotherapy in Relapse/Refractory Early T-Cell Precursor Acute Lymphoblastic Leukemia. Leuk Lymphoma (2021) 62(9):2292-4. doi: 10.1080/10428194.2021.1897807

79. Kong J, Chen N, Li M, Zhang J, Wu X, Zong L, et al. Venetoclax and Decitabine in Refractory TP53-Mutated Early T-Cell Precursor Acute Lymphoblastic Leukemia. Ann Hematol (2021). doi: 10.1007/s00277-02104530-y

80. Richard-Carpentier G, Jabbour E, Short NJ, Rausch CR, Savoy JM, Bose P, et al. Clinical Experience With Venetoclax Combined With Chemotherapy for Relapsed or Refractory T-Cell Acute Lymphoblastic Leukemia. Clin Lymphoma Myeloma Leuk (2020) 20:212-8. doi: 10.1016/j.clml.2019.09.608

81. Alexander T, Norris R, Jacobson A, Bensman L, Ross JA, Zhou L, et al. Safety and Efficacy of Venetoclax in Combination With Navitoclax in Adult and Pediatric Relapsed/Refractory Acute Lymphoblastic Leukemia and Lymphoblastic Lymphoma. Blood (2019) 134:285-5. doi: 10.1182/blood2019-126977

82. Maude SL, Dolai S, Delgado-Martin C, Vincent T, Robbins A, Selvanathan A, et al. Efficacy of JAK/STAT Pathway Inhibition in Murine Xenograft Models of Early T-Cell Precursor (ETP) Acute Lymphoblastic Leukemia. Blood (2015) 125:1759-67. doi: 10.1182/blood-2014-06-580480

83. Hills RK, Castaigne S, Appelbaum FR, Delaunay J, Petersdorf S, Othus M, et al. Addition of Gemtuzumab Ozogamicin to Induction Chemotherapy in Adult Patients With Acute Myeloid Leukaemia: A Meta-Analysis of Individual Patient Data From Randomised Controlled Trials. Lancet Oncol (2014) 15:986-96. doi: 10.1016/s1470-2045(14)70281-5

84. Golay J, Di Gaetano N, Amico D, Cittera E, Barbui AM, Giavazzi R, et al. Gemtuzumab Ozogamicin (Mylotarg) has Therapeutic Activity Against CD33 Acute Lymphoblastic Leukaemias In Vitro and In Vivo. Br J Haematol (2005) 128:310-7. doi: 10.1111/j.1365-2141.2004.05322.x
85. Tembhare PR, Sriram H, Khanka T, Chatterjee G, Panda D, Ghogale S, et al. Flow Cytometric Evaluation of CD38 Expression Levels in the Newly Diagnosed T-Cell Acute Lymphoblastic Leukemia and the Effect of Chemotherapy on Its Expression in Measurable Residual Disease, Refractory Disease and Relapsed Disease: An Implication for Anti-CD38 Immunotherapy. J Immunother Cancer (2020) 8:1-9. doi: 10.1136/jitc-2020000630

86. Bride KL, Vincent TL, Im SY, Aplenc R, Barrett DM, Carroll WL, et al. Preclinical Efficacy of Daratumumab in T-Cell Acute Lymphoblastic Leukemia. Blood (2018) 131:995-9. doi: 10.1182/blood-2017-07-794214

87. Mirgh S, Ahmed R, Agrawal N, Khushoo V, Garg A, Francis S, et al. Will Daratumumab be the Next Game Changer in Early Thymic Precursor-Acute Lymphoblastic Leukaemia? Br J Haematol (2019) 187:e33-5. doi: 10.1111/ bjh. 16154

88. Ofran Y, Ringelstein-Harlev S, Slouzkey I, Zuckerman T, Yehudai-Ofir D, Henig I, et al. Daratumumab for Eradication of Minimal Residual Disease in High-Risk Advanced Relapse of T-Cell/CD19/CD22-Negative Acute Lymphoblastic Leukemia. Leukemia (2020) 34:293-5. doi: 10.1038/s41375019-0548-z

89. Roizenblatt S, Cabanas-Pedro AC, Figueiredo MS. Immunomodulatory and Clinical Effects of Daratumumab in T-Cell Acute Lymphoblastic Leukaemia. Br J Haematol (2020) 191:e25-8. doi: 10.1111/bjh.16952

90. Fulcher J, Berardi P, Christou G, Villeneuve PJA, Bredeson C, Sabloff M. Nelarabine-Containing Regimen Followed by Daratumumab as an Effective Salvage Therapy and Bridge to Allogeneic Hematopoietic Stem Cell Transplantation for Primary Refractory Early T-Cell Precursor Lymphoblastic Leukemia. Leuk Lymphoma (2021) 62(9):2295-7. doi: 10.1080/10428194.2021.1901097

91. Venkataraman G, Aguhar C, Kreitman RJ, Yuan CM, Stetler-Stevenson M. Characteristic CD103 and CD123 Expression Pattern Defines Hairy Cell Leukemia: Usefulness of CD123 and CD103 in the Diagnosis of Mature BCell Lymphoproliferative Disorders. Am J Clin Pathol (2011) 136:625-30. doi: 10.1309/AJCPKUM9J4IXCWEU

92. Xue T, Budde LE. Immunotherapies Targeting CD123 for Blastic Plasmacytoid Dendritic Cell Neoplasm. Hematol Oncol Clin North Am (2020) 34:575-87. doi: 10.1016/j.hoc.2020.01.006

93. Perriello VM, Gionfriddo I, Rossi R, Milano F, Mezzasoma F, Marra A, et al. CD123 Is Consistently Expressed on NPM1-Mutated AML Cells. Cancers (Basel) (2021) 13:1-14. doi: 10.3390/cancers13030496

94. Angelova E, Audette C, Kovtun Y, Daver N, Wang SA, Pierce S, et al. CD123 Expression Patterns and Selective Targeting With a CD123-Targeted Antibody-Drug Conjugate (IMGN632) in Acute Lymphoblastic Leukemia. Haematologica (2019) 104:749-55. doi: 10.3324/haematol.2018.205252

95. Shah NN, Lee DW, Yates B, Yuan CM, Shalabi H, Martin S, et al. Long-Term Follow-Up of CD19-CAR T-Cell Therapy in Children and Young Adults With B-ALL. J Clin Oncol (2021) 39:1650-9. doi: 10.1200/JCO.20.02262

96. Lu W, Wei Y, Cao Y, Xiao X, Li Q, Lyu H, et al. CD19 CAR-T Cell Treatment Conferred Sustained Remission in B-ALL Patients With Minimal Residual Disease. Cancer Immunol Immunother (2021) 70(12):3501-11. doi: 10.1007/ s00262-021-02941-4

97. Cooper ML, Choi J, Staser K, Ritchey JK, Devenport JM, Eckardt K, et al. An "Off-the-Shelf" Fratricide-Resistant CAR-T for the Treatment of T Cell Hematologic Malignancies. Leukemia (2018) 32:1970-83. doi: 10.1038/ s41375-018-0065-5

98. Gomes-Silva D, Srinivasan M, Sharma S, Lee CM, Wagner DL, Davis TH, et al. CD7-Edited T Cells Expressing a CD7-Specific CAR for the Therapy of T-Cell Malignancies. Blood (2017) 130:285-96. doi: 10.1182/blood-2017-01761320

99. Png YT, Vinanica N, Kamiya T, Shimasaki N, Coustan-Smith E, Campana D. Blockade of CD7 Expression in T Cells for Effective Chimeric Antigen Receptor Targeting of T-Cell Malignancies. Blood Adv (2017) 1:2348-60. doi: 10.1182/bloodadvances.2017009928

100. Mamonkin M, Rouce RH, Tashiro H, Brenner MK. A T-Cell-Directed Chimeric Antigen Receptor for the Selective Treatment of T-Cell Malignancies. Blood (2015) 126:983-92. doi: 10.1182/blood-2015-02-629527

101. Neumann M, Heesch S, Schlee C, Schwartz S, Gokbuget N, Hoelzer D, et al. Whole-Exome Sequencing in Adult ETP-ALL Reveals a High Rate of 
DNMT3A Mutations. Blood (2013) 121:4749-52. doi: 10.1182/blood-201211-465138

102. Jin S, Cojocari D, Purkal JJ, Popovic R, Talaty NN, Xiao Y, et al. 5Azacitidine Induces NOXA to Prime AML Cells for Venetoclax-Mediated Apoptosis. Clin Cancer Res (2020) 26:3371-83. doi: 10.1158/10780432.CCR-19-1900

103. Bohl SR, Bullinger L, Rucker FG. Epigenetic Therapy: Azacytidine and Decitabine in Acute Myeloid Leukemia. Expert Rev Hematol (2018) 11:361-71. doi: 10.1080/17474086.2018.1453802

104. Farhadfar N, Li Y, May WS, Adams CB. Venetoclax and Decitabine for Treatment of Relapsed T-Cell Acute Lymphoblastic Leukemia: A Case Report and Review of Literature. Hematol Oncol Stem Cell Ther (2020) 14 (3):246-51. doi: 10.1016/j.hemonc.2019.10.002

105. Meng T, Yao Y, Xu Y, Xue S, Han Y, Tang X, et al. Salvage Therapy With Decitabine in Combination With Granulocyte Colony-Stimulating Factor, Low-Dose Cytarabine, and Aclarubicin in Patients With Refractory or Relapsed Early T-Cell Precursor Acute Lymphoblastic Leukemia. Hematol Oncol (2020) 38:834-7. doi: 10.1002/hon.2783

106. Neumann M, Heesch S, Gokbuget N, Schwartz S, Schlee C, Benlasfer O, et al. Clinical and Molecular Characterization of Early T-Cell Precursor Leukemia: A High-Risk Subgroup in Adult T-ALL With a High Frequency of FLT3 Mutations. Blood Cancer J (2012) 2:e55. doi: 10.1038/bcj.2011.49

107. Wu M, Li C, Zhu X. FLT3 Inhibitors in Acute Myeloid Leukemia. J Hematol Oncol (2018) 11:133. doi: 10.1186/s13045-018-0675-4
108. Neumann M, Coskun E, Fransecky L, Mochmann LH, Bartram I, Sartangi NF, et al. FLT3 Mutations in Early T-Cell Precursor ALL Characterize a Stem Cell Like Leukemia and Imply the Clinical Use of Tyrosine Kinase Inhibitors. PloS One (2013) 8:e53190. doi: 10.1371/journal.pone.0053190

109. De Raedt T, Beert E, Pasmant E, Luscan A, Brems H, Ortonne N, et al. PRC2 Loss Amplifies Ras-Driven Transcription and Confers Sensitivity to BRD4Based Therapies. Nature (2014) 514:247-51. doi: 10.1038/nature13561

Conflict of Interest: The authors declare that the research was conducted in the absence of any commercial or financial relationships that could be construed as a potential conflict of interest.

Publisher's Note: All claims expressed in this article are solely those of the authors and do not necessarily represent those of their affiliated organizations, or those of the publisher, the editors and the reviewers. Any product that may be evaluated in this article, or claim that may be made by its manufacturer, is not guaranteed or endorsed by the publisher.

Copyright $\odot 2021$ Sin and Man. This is an open-access article distributed under the terms of the Creative Commons Attribution License (CC BY). The use, distribution or reproduction in other forums is permitted, provided the original author(s) and the copyright owner(s) are credited and that the original publication in this journal is cited, in accordance with accepted academic practice. No use, distribution or reproduction is permitted which does not comply with these terms. 